Federal Reserve Bank of Dallas

Globalization and Monetary Policy Institute

Working Paper No. 21

http://www.dallasfed.org/assets/documents/institute/wpapers/2008/0021.pdf

\title{
Vertical Specialization and International Business Cycle Synchronization ${ }^{*}$
}

\author{
Costas Arkolakis \\ Yale University and NBER \\ Ananth Ramanarayanan \\ Federal Reserve Bank of Dallas \\ October 2008 \\ Revised: September 2009
}

\begin{abstract}
We explore the impact of vertical specialization - trade in goods across multiple stages of production - on the relationship between trade and business cycle synchronization across countries. We develop an international business cycle model in which the degree of vertical specialization varies with trade barriers. With perfect competition, we show analytically that fluctuations in measured total factor productivity are not linked across countries through trade. In numerical simulations, we find little dependence of business cycle synchronization on trade intensity. An extension of the model to allow for imperfect competition has the potential to resolve these shortcomings.
\end{abstract}

JEL codes: F41, E32

\footnotetext{
* Costas Arkolakis, Department of Economics, Yale University, P.O. Box 208264, New Haven, CT 06520-8264. costas.arkolakis@yale.edu. Ananth Ramanarayanan, Research Department, Federal, Reserve Bank of Dallas, 2200 N. Pearl St, Dallas, TX 75201. Ananth.ramanaryanan@dal.frb.org. We are grateful to Cristina Arellano and Timothy Kehoe for valuable advice. For helpful comments, we also thank two anonymous referees, as well as Simona Cociuba, Jonathan Eaton, Patrick Kehoe, Steve Redding, Olga Timoshenko and Kei-Mu Yi. A previous version of this paper circulated under the title "Endogenous Specialization, Intermediate Goods, and International Business Cycles." The views in this paper are those of the authors and do not necessarily reflect the views of the Federal Reserve Bank of Dallas or the Federal Reserve System.
} 


\section{Introduction}

In recent empirical work, several authors have documented a link between international trade and cross-country business cycle synchronization. Frankel \& Rose (1998) established that country pairs that trade more exhibit on average higher correlations in their business cycles, as measured by fluctuations in GDP. ${ }^{1}$ However, Kose \& Yi (2001) and (2006) have illustrated what they call a trade-comovement puzzle: standard international real business cycle models along the lines of Backus, Kehoe \& Kydland (1994) cannot quantitatively account for the relationship between trade and business cycle comovement.

In this paper, we develop an international business cycle model augmented with vertical specialization - i.e., the production of goods in multiple stages spread across countries - and quantitatively assess its ability to generate stronger business cycle synchronization between countries that trade more. In addressing the empirical facts behind the trade-comovement puzzle, several authors have suggested that it is not only the volume of trade, but particular features of specialization patterns and industrial structure associated with increased trade that lead to business cycle synchronization. Frankel \& Rose (1998) conjectured that intra-industry trade tends to make countries more correlated, while Kose \& Yi (2001) have suggested that vertical specialization may be the key linkage that synchronizes business cycles of countries with close trade relationships. The intuition is that if closer trade relationships are characterized by tighter links in the chain of production, fluctuations in one economy should be transmitted more to the other. ${ }^{2}$

\footnotetext{
${ }^{1}$ Recent papers that have confirmed this finding are Clark \& Van Wincoop (2001) and Baxter \& Kouparitsas (2005).

${ }^{2}$ Indeed, $\mathrm{Ng}$ (2007) finds that direct measures of bilateral vertical specialization are related to increased business cycle correlation, and that intra-industry trade plays no significant role once vertical specialization is taken into account. In addition, Di Giovanni \& Levchenko (2008), using cross-country industry-level data,
} 
The main innovation of our work is to introduce producer heterogeneity with two stages of production into an international business cycle model along the lines of Backus et al. (1994). In this respect, our model is similar to Yi (2003) and (2009), extended to an environment with aggregate uncertainty. In each stage, the degree of specialization by each country is endogenously determined. As a result, each country requires inputs from the other to produce final output. Since this link is stronger when countries trade a wider range of goods, this vertical specialization provides a potential mechanism for the model to generate increased business cycle correlation with higher trade.

We first consider a model with perfect competition, as in the Ricardian model of Eaton \& Kortum (2002). Qualitatively, this model generates an increase in GDP correlation with higher trade intensity, but falls short quantitatively compared to the data. There are two findings that explain this result: one analytical, and one numerical. The analytical finding is that, when standard national income accounting methods are used to construct real GDP, fluctuations in measured Total Factor Productivity (TFP) in each country depend only on domestic shocks, to a first-order approximation. Hence, trade links do not transmit technology shocks across countries directly into measured productivity. Changes in real GDP, though, are accounted for by changes in TFP as well as changes in factor inputs; the numerical finding is that the correlation across countries of changes in inputs is not sufficient to generate substantial correlation in real GDP, nor a significant dependence of business cycle correlation on trade intensity.

These results allow us to identify the features of the model that lead standard accounting methods to understate the impact of trade on international business cycle transmission. Most 
notable of these features is the fact that perfect competition prevents efficiency differences across producers from translating into differences in measured productivity. To address this issue, we introduce imperfect competition following Bernard, Eaton, Jensen \& Kortum (2003), allowing for markups to vary across producers with different efficiency. In this model, efficiency differences do translate into measured productivity differences, and we find that this new channel gives the model the potential to generate cross-country correlations in measured TFP, and thus real GDP, that increase with trade intensity.

This paper is most closely related to recent papers that attempt to account for the tradecomovement relationship. Burstein, Kurz \& Tesar (2008) show that allowing for production sharing among countries can deliver tighter business cycle synchronization. ${ }^{3}$ Our results suggest that for looking at real GDP, relaxing key assumptions such as constant elasticity of substitution in preferences and perfect competition could be crucial for changing the implications of trade intensity for business cycle behavior. Drozd \& Nosal (2008) deviate from the standard neoclassical framework and address the link between trade and comovement in a model featuring a low short-run price elasticity of trade coexisting with a high long-run price elasticity. ${ }^{4}$

The rest of the paper is organized as follows: Section II. lays out our model and section III. discusses the structure of vertical specialization. Section IV. discusses the dynamics of real GDP and measured productivity. Section V. reviews some data on vertical specialization and links various measures to our model. Section VI. describes our numerical experiments with

\footnotetext{
${ }^{3}$ Following a different approach, Huang \& Liu (2007) argue that multiple stages of production increase business cycle comovement in the presence of nominal rigidities.

${ }^{4}$ In related work, Bergin, Feenstra \& Hanson (2007) combine a model of outsourcing of production with non-CES preferences to account for the variance of output in outsourcing industries in Mexico compared to the US.
} 
perfect competition, and Section VII. discusses the extension with imperfect competition and variable markups. Section VIII. concludes.

\section{Setup of the Model}

Goods are produced in two stages with the second stage of production (production of "final goods") using goods produced in the first stage ("intermediate goods"). The presence of Ricardian comparative advantage, which we model as in Eaton \& Kortum (2002), leads countries to endogenously specialize across a continuum of goods in each stage.

The time horizon is infinite and discrete, and periods are indexed by $t=0,1, \ldots$ In each country, there are two sectors of production: a tradeable sector and a nontradeable sector. There is a continuum of measure one of goods in both stages of tradeable production. To economize on notation, except where noted below, we index both intermediate and final goods in the tradeable sector by $\omega$, although an intermediate good labelled $\omega$ and a final good labelled $\omega$ are distinct commodities. We use subscripts to refer to stages of production, $s=1,2$, and time periods, and we use superscripts to refer to countries, $i, j=1,2$. When a variable has a double superscript, the first index refers to the source country and the second refers to the destination.

\section{Production of Tradeable Goods}

Each first-stage intermediate input $\omega$ can be produced in country $i$ using a constant returns to scale technology combining physical capital and labor with efficiency denoted by $A_{1 t}^{i} z_{1}^{i}(\omega)$. $A_{1 t}^{i}$ is a country-specific time-varying productivity shock common to all intermediate goods producers in country $i$, and $z_{1}^{i}(\omega)$ is a good-specific efficiency that is constant over time. 
Output of each intermediate good $\omega$ produced by country $i$ is given by:

$$
y_{1 t}^{i}(\omega)=A_{1 t}^{i} z_{1}^{i}(\omega) k_{1 t}^{i}(\omega)^{\alpha} \ell_{1 t}^{i}(\omega)^{1-\alpha}
$$

where $k_{1 t}^{i}(\omega)$ and $\ell_{1 t}^{i}(\omega)$ denote capital and labor, respectively, used in the production of $\operatorname{good} \omega$, and $\alpha \in(0,1)$.

The minimum unit cost of producing intermediate good $\omega$ in country $i$ is:

$$
q_{1 t}^{i}(\omega)=\frac{q_{1 t}^{i}}{z_{1}^{i}(\omega)}
$$

where $q_{1 t}^{i}$ is the cost of the input bundle scaled by aggregate productivity in the first stage:

$$
q_{1 t}^{i}=\frac{\left(r_{t}^{i}\right)^{\alpha}\left(w_{t}^{i}\right)^{1-\alpha}}{A_{1 t}^{i} \alpha^{\alpha}(1-\alpha)^{1-\alpha}}
$$

Here, $w_{t}^{i}$ denotes the wage and $r_{t}^{i}$ is the rental rate of capital in country $i$.

Purchasers of intermediate goods in each country buy each good from the source country that offers the lowest price after accounting for trade costs. We adopt the standard "iceberg" cost formulation, so that delivering one unit of any stage- $s$ good from country $i$ to country $j$ requires shipping $\tau_{s}^{i j}$ units, with $\tau_{s}^{i i}=1$ and $\tau_{s}^{i j} \geq 1$. Therefore, the price at which country $j$ purchases intermediate good $\omega$ is given by:

$$
p_{1 t}^{j}(\omega)=\min \left\{q_{1 t}^{i}(\omega) \tau_{1}^{i j}: i=1,2\right\} .
$$


The technology for producing output of final good $\omega$ is: ${ }^{5}$

$$
y_{2 t}^{i}(\omega)=A_{2 t}^{i} z_{2}^{i}(\omega)\left(k_{2 t}^{i}(\omega)^{\alpha} \ell_{2 t}^{i}(\omega)^{1-\alpha}\right)^{\eta}\left(\int m_{t}^{i}\left(\omega, \omega^{\prime}\right)^{\frac{\sigma-1}{\sigma}} d \omega^{\prime}\right)^{\frac{(1-\eta) \sigma}{\sigma-1}},
$$

where $k_{2 t}^{i}(\omega)$, and $\ell_{2 t}^{i}(\omega)$ denote capital and labor used in the production of final good $\omega$, $A_{2 t}^{i}$ and $z_{2}^{i}(\omega)$ are time-varying and good-specific efficiency for final goods, respectively, and $m_{t}^{i}\left(\omega, \omega^{\prime}\right)$ is the use of intermediate good $\omega^{\prime}$ in the production of final good $\omega$. The parameter $\sigma>0$ is the elasticity of substitution between different intermediate inputs. We define the aggregate composite of intermediate goods used in production of final tradeable goods as:

$$
M_{T t}^{i}=\int\left(\int m_{t}^{i}\left(\omega, \omega^{\prime}\right)^{\frac{\sigma-1}{\sigma}} d \omega^{\prime}\right)^{\frac{\sigma}{\sigma-1}} d \omega
$$

where the subscript $T$ distinguishes variables for the tradeable sector from corresponding variables for the nontradeable sector, discussed below.

The unit cost of production for final good $\omega$ is given by

$$
q_{2 t}^{i}(\omega)=\frac{q_{2 t}^{i}}{z_{2}^{i}(\omega)},
$$

where

$$
q_{2 t}^{i}=\frac{1}{A_{2 t}^{i}}\left(\frac{\left(r_{t}^{i}\right)^{\alpha}\left(w_{t}^{i}\right)^{1-\alpha}}{\eta \alpha^{\alpha}(1-\alpha)^{1-\alpha}}\right)^{\eta}\left(\frac{P_{1 t}^{i}}{1-\eta}\right)^{1-\eta}
$$

\footnotetext{
${ }^{5}$ Unless otherwise noted, integration is over the entire set of goods in the relevant stage of production.
} 
Here, the term $P_{1 t}^{i}$ denotes the price for the intermediate goods bundle:

$$
P_{1 t}^{i}=\left(\int p_{1 t}^{i}(\omega)^{1-\sigma} d \omega\right)^{1 /(1-\sigma)}
$$

Similar to first-stage goods, final goods are also purchased in each country from the source offering the lowest price adjusted for trade costs. Thus, the price of final good $\omega$ in country $j$ is:

$$
p_{2 t}^{j}(\omega)=\min \left\{q_{2 t}^{i}(\omega) \tau_{2}^{i j}: i=1,2\right\}
$$

Final goods are purchased by households to form composite consumption and investment of tradeable goods, which we denote

$$
\begin{aligned}
& X_{T t}^{j}=\left(\int x_{T t}^{j}(\omega)^{\frac{\sigma-1}{\sigma}} d \omega\right)^{\frac{\sigma}{\sigma-1}}, \\
& C_{T t}^{j}=\left(\int c_{T t}^{j}(\omega)^{\frac{\sigma-1}{\sigma}} d \omega\right)^{\frac{\sigma}{\sigma-1}} .
\end{aligned}
$$

Therefore, the price index for final tradeable goods has the same form as (9), and is given by:

$$
P_{2 t}^{i}=\left(\int p_{2 t}^{i}(\omega)^{1-\sigma} d \omega\right)^{1 /(1-\sigma)}
$$

In the next section, we impose further structure on the distribution of good-specific efficiencies, and derive how these assumptions shape the pattern of trade and the prices paid for goods in each country. 


\section{Technology structure for tradeable goods}

We follow the probabilistic representation of Eaton \& Kortum (2002) for good-specific efficiencies. For each country $i$, stage $s$, and $\operatorname{good} \omega, z_{s}^{i}(\omega)$ is drawn from a Fréchet distribution with cumulative distribution function:

$$
F_{s}^{i}(z)=e^{-T_{s}^{i} z^{-\theta}},
$$

where $T_{s}^{i}>0$ and $\theta>1$. Efficiency draws are independent across goods, stages, and countries. The probability that a particular stage- $s$ good $\omega$ can be produced in country $i$ with efficiency less than or equal to $z$ is given by $F_{s}^{i}(z)$. Since draws are independent across the continuum of goods, $F_{s}^{i}(z)$ also denotes the fraction of stage- $s$ goods that country $i$ is able to produce with efficiency at most $z$.

As in Eaton \& Kortum (2002), the cross country differences in $T_{s}^{i}$ reflect absolute advantage in the production of goods in each stage: a country with a higher $T_{s}^{i}$ draws efficiencies for all goods in a given stage from a better distribution. The parameter $\theta$ determines the dispersion of efficiency draws, and hence governs heterogeneity across goods and leads to comparative advantage within each stage of production. In addition, since the terms $T_{s}^{i}$ may differ for $s=1,2$, our technological structure allows for comparative advantage across stages, determined by the ratio $T_{1}^{i} / T_{2}^{i}$ across countries. A country with a higher $T_{1}^{i} / T_{2}^{i}$, for example, is relatively more productive in intermediate inputs.

As Eaton \& Kortum (2002) show, the distribution of prices of stage-1 goods that country

$i$ offers to country $j$ is equal to $G_{s t}^{i j}(p)=1-e^{-T_{s}^{i}\left(q_{s t}^{i j}\right)^{-\theta} p^{\theta}}$, where $q_{s t}^{i j}=q_{s t}^{i} \tau_{s}^{i j}$. The probability that country $j$ is able to purchase a certain good at price below $p$ is the probability that either 
source country offers country $j$ a price below $p$, that is, the probability that $\min \left\{q_{s t}^{i j}, q_{s t}^{j j}\right\} \leq p$. Therefore, the overall distribution of prices of stage- $s$ goods available in country $j$ is

$$
G_{s t}^{j}(p)=1-e^{-\Phi_{s t}^{j} p^{\theta}}
$$

where

$$
\Phi_{s t}^{j} \equiv T_{s}^{i}\left(q_{s t}^{i j}\right)^{-\theta}+T_{s}^{j}\left(q_{s t}^{j j}\right)^{-\theta}
$$

Since the only dimension of heterogeneity across goods in a given stage is efficiency, we can aggregate across goods by aggregating across efficiency levels or across prices. With this transformation, the price index for stage- $s$ goods can be written as $\left(P_{s t}^{j}\right)^{1-\sigma}=\int_{0}^{\infty} p^{1-\sigma} d G_{s t}^{j}(p)$, which, using the distributions (14) is:

$$
P_{s t}^{j}=\left[\Gamma\left(\frac{\theta+1-\sigma}{\theta}\right)\right]^{1 /(1-\sigma)}\left(\Phi_{s t}^{j}\right)^{-1 / \theta}
$$

where $\Gamma$ is the Gamma function, $\Gamma(a)=\int_{0}^{\infty} t^{a-1} e^{-t} d t$.

The probability that country $j$ buys a certain good from country $i$, or alternatively the fraction of goods that country $j$ buys from country $i$, is given by the probability that $q_{s t}^{i j} \leq \min \left\{q_{s t}^{i j}, q_{s t}^{j j}\right\}$. As Eaton \& Kortum (2002) show, this is equal to:

$$
\lambda_{s t}^{i j}=\frac{T_{s}^{i}\left(q_{s t}^{i j}\right)^{-\theta}}{\Phi_{s t}^{j}} .
$$

In addition, because the distribution of stage- $s$ goods actually purchased by country $j$ from country $i$ is equal to the overall price distribution $G_{s t}^{j}$, the fraction $\lambda_{s t}^{i j}$ of goods purchased 
from country $i$ is also equal to the fraction of country $j$ 's total expenditures on stage- $s$ goods that it spends on goods from country $i$.

Production of nontradeable goods

Each country also produces a nontradeable good according to the following technology:

$$
Y_{N t}^{i}=A_{N t}^{i}\left(\left(K_{N t}^{i}\right)^{\alpha}\left(L_{N t}^{i}\right)^{1-\alpha}\right)^{\eta}\left(\int m_{N t}^{i}(\omega)^{\frac{\sigma-1}{\sigma} d \omega}\right)^{\frac{(1-\eta) \sigma}{\sigma-1}}
$$

where $m_{N t}^{i}(\omega)$ is the quantity of intermediate good $\omega$ purchased for use in the production of the nontradeable good. The composite intermediate inputs used in nontradeable production is

$$
M_{N t}^{i}=\left(\int m_{N t}^{i}(\omega)^{\frac{\sigma-1}{\sigma}} d \omega\right)^{\frac{\sigma}{\sigma-1}}
$$

The unit cost of producing nontradeable goods is

$$
P_{N t}^{i}=\frac{1}{A_{N t}^{i}}\left(\frac{\left(r_{t}^{i}\right)^{\alpha}\left(w_{t}^{i}\right)^{1-\alpha}}{\eta \alpha^{\alpha}(1-\alpha)^{1-\alpha}}\right)^{\eta}\left(\frac{P_{1 t}^{i}}{1-\eta}\right)^{1-\eta}
$$

\section{Households}

Each country is populated by an infinitely-lived representative household which values sequences of consumption of tradeable final goods, consumption of nontradeable goods, and leisure, according to the following preferences:

$$
E \sum_{t=0}^{\infty} \beta^{t}\left(\left(\left(C_{T t}^{i}\right)^{\gamma}\left(C_{N t}^{i}\right)^{1-\gamma}\right)^{\mu}\left(1-L_{t}^{i}\right)^{1-\mu}\right)^{1-\varepsilon} /(1-\varepsilon)
$$


where $L$ denotes the fraction of time devoted to labor supplied in domestic production, $C_{T}$ denotes the tradeable composite consumption defined in (11) and $C_{N}$ denotes consumption of nontradeable goods. $E$ denotes the expectation over the entire time horizon, and $\beta \in(0,1)$ is the household's discount factor. The parameter $\gamma \in(0,1)$ determines the fraction of aggregate expenditure on tradeable goods and $\varepsilon>0$ determines the household's elasticity of substitution across dates and states of the world.

The household also purchases tradeable and nontradeable investment goods, $X_{T t}^{i}$ and $X_{N t}^{i}$, that are bundled to augment the aggregate capital stock $K_{t}^{i}$ :

$$
K_{t+1}^{i}=\left(X_{T t}^{i}\right)^{\gamma}\left(X_{N t}^{i}\right)^{1-\gamma}+(1-\delta) K_{t}^{i}
$$

where $\delta$ is the depreciation rate of capital and the fraction $\gamma$ of investment expenditures are spent on tradeable goods. We assume that the household spends a constant share of income on nontradeable consumption and nontradeable investment to avoid needing excessively high transportation costs to generate realistic levels of trade.

The household receives income from selling labor services and renting capital to firms. We assume that countries do not trade financial assets - that is, trade in goods is balanced in each period - so the total expenditure of each country is constrained by its income: ${ }^{6}$

$$
P_{2 t}^{i}\left[C_{T t}^{i}+X_{T t}^{i}\right]+P_{N t}^{i}\left[C_{N t}^{i}+X_{N t}^{i}\right] \leq w_{t}^{i} L_{t}^{i}+r_{t}^{i} K_{t}^{i}
$$

\footnotetext{
${ }^{6}$ The findings in Heathcote \& Perri (2002) suggest that models with financial autarky generate international comovement that is closer to the data than models with complete financial markets. Models with complete markets have a strong risk-sharing channel from which we wish to abstract to isolate the mechanisms in our model.
} 


\section{Market Clearing and Equilibrium}

Let $\Omega_{s t}^{i}$ denote the set of stage-s goods which country $i$ produces. We define total capital stocks and labor in each country $i=1,2$ and in each tradeable stage $s=1,2$ as

$$
\begin{aligned}
K_{s t}^{i} & =\int_{\Omega_{s t}^{i}} k_{s t}^{i}(\omega) d \omega, \\
L_{s t}^{i} & =\int_{\Omega_{s t}^{i}} \ell_{s t}^{i}(\omega) d \omega .
\end{aligned}
$$

At each date $t$, the total supply of capital and labor by households equals the demand from producers,

$$
\begin{aligned}
K_{t}^{i} & =K_{1 t}^{i}+K_{2 t}^{i}+K_{N t}^{i}, \\
L_{t}^{i} & =L_{1 t}^{i}+L_{2 t}^{i}+L_{N t}^{i} .
\end{aligned}
$$

We use the expenditure shares defined in (17) to write aggregated market clearing conditions for goods in each stage and sector. Country $i$ 's expenditure on goods from country $j$ equal a fraction $\lambda_{s t}^{j i}$ for stage- $s$ goods. Since producers are perfectly competitive, the income paid to factors in the first stage equals the value of first-stage production in country $i$, and the income paid to factors in production of final goods equals a fraction $\eta$ of the value of final goods production. Therefore, for tradeable goods,

$$
\begin{aligned}
& w_{t}^{i} L_{1 t}^{i}+r_{t}^{i} K_{1 t}^{i}=\lambda_{1 t}^{i i} P_{1 t}^{i}\left(M_{T t}^{i}+M_{N t}^{i}\right)+\lambda_{1 t}^{i j} P_{1 t}^{j}\left(M_{T t}^{j}+M_{N t}^{j}\right), \\
& w_{t}^{i} L_{2 t}^{i}+r_{t}^{i} K_{2 t}^{i}=\eta\left(\lambda_{2 t}^{i i} P_{2 t}^{i}\left(C_{T t}^{i}+X_{T t}^{i}\right)+\lambda_{2 t}^{i j} P_{2 t}^{i j}\left(C_{T t}^{j}+X_{T t}^{j}\right)\right),
\end{aligned}
$$


and for nontradeable goods,

$$
w_{t}^{i} L_{N t}^{i}+r_{t}^{i} K_{N t}^{i}=\eta P_{N t}^{i}\left(C_{N t}^{i}+X_{N t}^{i}\right), i=1,2
$$

An equilibrium consists of stochastic processes for prices and quantities such that households' utility is maximized subject to (21) and (22), producers' costs are minimized, and the market clearing conditions for goods and factor inputs are satisfied each period. We solve for an equilibrium in terms of consumption, investment, and intermediate input expenditures, capital and labor supplies, factor prices, and composite price indices, with quantities aggregated across the continuum of goods in the case of the two tradeable stages. We use a standard linear approximation method to solve for recursive decision rules in the neighborhood of the model's deterministic steady state. ${ }^{7}$

\section{Vertical Specialization Structure}

We now briefly compare the vertical specialization structure in our model to related ways of specifying this feature. We will focus our comparison on three recent contributions, Eaton \& Kortum (2002), Burstein et al. (2008), and Yi (2009).

Eaton \& Kortum (2002) assume that each good is used as both an intermediate and a final good. ${ }^{8}$ Intermediate inputs are combined to produce output in the same way as in our second stage technology, summarized in (5). Their modeling of intermediate inputs is simple in that it does not incorporate any notion of specialization into different stages of

\footnotetext{
${ }^{7}$ Similar approaches are used by Ghironi \& Melitz (2005) and Naknoi (2008), in models with a continuum of goods.

${ }^{8}$ A similar intermediate inputs structure has been explored by Krugman \& Venables (1995).
} 
production. Specialization in different stages does exist in Burstein et al. (2008) who employ an Armington-aggregator structure in which intermediate inputs from different countries are combined with a fixed elasticity of substitution into a final good. However, the pattern of specialization is fixed in that countries do not specialize in the production of the goods in which they are most efficient.

An alternative model with endogenous specialization is the one used in Yi (2003) and (2009), in which there are two stages, but each second-stage good uses exactly one first-stage good as an input, not a bundle of all the goods. Our intermediate input structure can be considered as a combination of Eaton \& Kortum (2002) and the two-stage structure of Yi (2009), and our assumption that all final producers use the same bundle of inputs allows us to solve the model using the results in Eaton \& Kortum (2002). Our model incorporates in a parsimonious way two of the important features of Yi's setup - endogenous specialization and trade in intermediate inputs - that could create additional linkages in the production processes of countries through increased trade.

There are two differences between our setup and that in Yi (2009). First, in our model, the degree of vertical specialization depends on trade barriers, but is the same for all goods. In Yi (2009), only a fraction of goods are produced with vertical specialization, and this fraction depends on trade intensity. Second, in Yi (2009), for the goods that are vertically specialized, a decrease in the price of imports would make both the input and output price in the second stage drop by a proportional amount. This mechanism generates large changes in trade shares for goods that are vertically specialized, or goods that become vertically specialized as a result. In our model, since each good uses the same composite of intermediate inputs, a drop in import prices causes the input price index and the output price of any final good to 
drop by only a fraction of the import price drop, and the elasticity of trade shares to import prices is the same for all goods.

\section{Real GDP and Productivity in the Model}

Compared to standard international business cycle models, our model contains additional potential channels of international transmission of fluctuations through trade. The presence of vertical specialization links countries' production processes, and the degree of specialization increases with trade intensity, so that countries that trade more have production processes that are more closely linked.

In standard international business cycle models in which all value-added is created in a single stage of production, technology shocks are transmitted across countries through the imperfect substitutability of goods: a country that receives a favorable shock demands more imports as well as domestic goods for consumption and investment, so its trading partner produces more. In our model, there is an additional effect from having two stages of production: a country with a favorable shock offers its trading partner lower prices for intermediate inputs, which makes production of final goods more efficient, as the same amount of output can be produced with lower input expenditures. If the degree of vertical specialization increases with trade intensity, then there is more potential for a country to benefit from foreign technology improvements in this way. Additionally, due to endogenous specialization, countries produce the goods in which they are most efficient, so that foreign productivity improvements cause increased specialization into more efficiently produced goods at home.

To assess the potential impact of these mechanisms on business cycle comovement, we need to construct a measure of real value added, or GDP. In order to compare the model's 
predictions to data, we construct a measure of real GDP from the model's output comparable with standard national accounting methods. In our model, since there is a continuum of goods and changing trade patterns, we have some choice regarding how to compute aggregate quantities. Since our results depend heavily on the method of GDP measurement, we dwell on this point a bit here: in the first subsection below, we explain the definitions of aggregate statistics we use, and in the second subsection, we derive some of the implications of our choices for fluctuations in aggregate productivity.

\section{National Accounts Statistics in the Model}

We construct an analogue of real GDP, that is, GDP measured in base period prices, as reported in actual data by national statistical agencies. In order to do this in a way that is as close as possible to the methods used by these agencies, we follow the recommendations in the UN's System of National Accounts 1993 (SNA93).

We define nominal GDP at current prices as aggregate value-added, or the difference between the total value of gross output less total expenditures on intermediate inputs. Gross output at current producer prices is given by:

$$
Z_{t}^{i}=\int_{\Omega_{1 t}^{i}} q_{1 t}^{i}(\omega) y_{1 t}^{i}(\omega) d \omega+\int_{\Omega_{2 t}^{i}} q_{2 t}^{i}(\omega) y_{2 t}^{i}(\omega) d \omega+P_{N t}^{i} Y_{N t}^{i},
$$

and expenditure on intermediate inputs, valued at purchaser prices, is given by:

$$
I_{t}^{i}=\int_{\Omega_{2 t}^{i}}\left(\int p_{1 t}^{i}\left(\omega^{\prime}\right) m_{t}^{i}\left(\omega, \omega^{\prime}\right) d \omega^{\prime}\right) d \omega+\int p_{1 t}^{i}(\omega) m_{N t}^{i}(\omega) d \omega .
$$


GDP at current prices is then $Y_{t}^{i}=Z_{t}^{i}-I_{t}^{i}$.

To construct real GDP as measured in the data, we reconstruct the above formulas using constant, base-period prices for each good. Real gross output is:

$$
\mathcal{Z}_{t}^{i}=\int_{\Omega_{1 t}^{i}} \tilde{q}_{10}^{i}(\omega) y_{1 t}^{i}(\omega) d \omega+\int_{\Omega_{2 t}^{i}} \tilde{q}_{20}^{i}(\omega) y_{2 t}^{i}(\omega) d \omega+P_{N 0}^{i} Y_{N t}^{i},
$$

where $\tilde{q}_{s 0}^{i}(\omega)$ is a base period producer price, defined below. Real expenditures on intermediate inputs are:

$$
\mathcal{I}_{t}^{i}=\int_{\Omega_{2 t}^{i}}\left(\int p_{10}^{i}\left(\omega^{\prime}\right) m_{t}^{i}\left(\omega, \omega^{\prime}\right) d \omega^{\prime}\right) d \omega+\int p_{10}^{i}(\omega) m_{N t}^{i}(\omega) d \omega
$$

where $p_{10}^{i}(\omega)$ is the base period purchaser's price. Real GDP is then defined as $\mathcal{Y}_{t}^{i}=\mathcal{Z}_{t}^{i}-\mathcal{I}_{t}^{i}$. Effectively, we are using what national statistical agencies refer to as a "double-deflation" method, deflating the current price values of gross output and intermediate consumption each by their own deflators.

A practical problem that this method raises is that country-specific period-0 producer prices, $\tilde{q}_{s 0}^{i}(\omega)$, are not defined for all goods, due to the fact that specialization patterns change in the model. For example, it may be the case that good $\omega$ is produced in country 1 in period $t$, but was not produced by country 1 in period 0 ; country 1 would have imported the good in period 0 . In this case, it is not obvious at what price we should value country 1's output of good $\omega$ in period $t$ when calculating real gross output. On the one hand, the SNA 93 recommends (paragraph 16.53) using average price changes of similar products as a proxy for the change in price of a new good between the base period and the current period; 
adapting this interpretation in our model would mean using country 1's price of selling the good to itself in period $0, q_{s 0}^{1}(\omega)$. On the other hand, if we use the price at which the good was imported in period 0 , then the product account (gross output less intermediate inputs) is consistent with the expenditure account (consumption plus investment less net exports), because the base period consumer price is unambiguously equal to the import price. We proceed with the latter assumption, but this choice has essentially no effect on our results.

\section{Measured TFP correlation}

In Section VI., we perform several numerical experiments to evaluate the extent to which increased trade intensity affects business cycle synchronization in the presence of vertical specialization. In this section, however, we show that, in one important respect, trade in our model does not make countries more correlated: changes in measured TFP, constructed in our model using real GDP as defined above, are not linked across countries through international trade. That is, although measured TFP is an endogenous object in our model, there is no endogenous link between TFP across countries, and hence no dependence on trade intensity of the correlation in TFP. When measuring aggregate accounting statistics as in the data, the dynamics of TFP are pinned down by exogenous factors alone. In addition, the intuition behind the result suggests that it holds for a wide class of dynamic models with endogenous specialization and trade in intermediate goods. Without comovement in TFP, our model can produce endogenous comovement in GDP, but to a small degree, as we show in the next section. ${ }^{9}$

\footnotetext{
${ }^{9}$ This is consistent with the finding in Kose \& Yi (2006), that the standard model can account for the trade-comovement puzzle if it is exogenously imposed that the correlation of TFP increases with trade intensity.
} 
Our result can be stated as follows:

Proposition 1 Let variables with ^ denote log deviations from the steady state. Measured TFP, defined by:

$$
\mathcal{A}_{t}^{i}=\frac{\mathcal{Y}_{t}^{i}}{\left(K_{t}^{i}\right)^{\alpha}\left(L_{t}^{i}\right)^{1-\alpha}},
$$

follows, to a first order approximation:

$$
\hat{\mathcal{A}}_{t}^{i}=(1-\eta) \hat{A}_{1 t}^{i}+\gamma \hat{A}_{2 t}^{i}+(1-\gamma) \hat{A}_{N t}^{i}
$$

A sketch of the proof of this and the next proposition is provided in the appendix. The proposition is related to Hulten (1978), who showed that, in a multi-sector neoclassical closed economy with intermediate inputs, aggregate TFP evolves as a weighted average of sectoral productivity growth, with the weights given by sectoral gross output shares of GDP. Equation (32) shows that aggregate TFP in our model behaves exactly as in a three-sector version of the closed economy models that Hulten considers, with only one of the sectors supplying intermediate inputs.

The intuition for this stark result is straightforward, given the assumptions used in aggregating value-added across goods to construct real GDP. First, because we use good-specific prices in valuing the output of each producer, efficiency differences across goods do not show up in the value of output: in the presence of perfect competition, a producer with higher efficiency simply charges a proportionally lower price, so the measured value of output per unit of input does not vary across producers. ${ }^{10}$ Bernard et al. (2003) and Gibson (2006) raise the

\footnotetext{
${ }^{10}$ This is only true for goods that are produced in the same country in a period $t$ and the base period. However, to a first-order approximation, the goods that switch country of production contribute zero to
} 
same point regarding the effect of reallocation that occurs in response to trade liberalization in models with heterogeneous producers and monopolistic competition. Second, by using base period prices, the fluctuations in the value of income from movements in factor costs and prices do not show up in the computation of real GDP, a point made by Kehoe \& Ruhl (2008). Even with intermediate goods, the gains in efficiency that result from purchasing imported inputs at cheaper prices are removed by valuing inputs at base period prices. ${ }^{11}$

To show that the accounting method is the reason that foreign productivity shocks do not affect domestic TFP, in the next proposition we show that a welfare-based measure of productivity does capture the effects of foreign productivity shocks through trade.

Proposition 2 Define "welfare-based real income" and "welfare-based productivity" as:

$$
\begin{aligned}
\tilde{Y}_{t}^{i} & =\frac{\left(w_{t}^{i} L_{t}^{i}+r_{t}^{i} K_{t}^{i}\right)}{\left(P_{2 t}^{i}\right)^{\gamma}\left(P_{N t}^{i}\right)^{1-\gamma} \gamma^{-\gamma}(1-\gamma)^{\gamma-1}} \\
\tilde{A}_{t}^{i} & =\frac{\tilde{Y}_{t}^{i}}{\left(K_{t}^{i}\right)^{\alpha}\left(L_{t}^{i}\right)^{1-\alpha}} .
\end{aligned}
$$

Then, for some constant $\Delta^{i}$,

$$
\tilde{A}_{t}^{i}=\Delta^{i}\left(\lambda_{1 t}^{i i}\right)^{-(1-\eta) / \theta}\left(\lambda_{2 t}^{i i}\right)^{-\gamma / \theta}\left(A_{1 t}^{i}\right)^{1-\eta}\left(A_{2 t}^{i}\right)^{\gamma}\left(A_{N t}^{i}\right)^{1-\gamma}
$$

A welfare-based measure of productivity increases when the share of goods that a country buys from itself, $\lambda_{s t}^{i i}$, decreases in either stage. Foreign productivity improvements generate

changes in real GDP. Interestingly, the distributions of efficiencies in each stage do not play any role in deriving this result. As long as we look at first-order effects, where the goods that switch contribute zero to changes in real GDP, the proof goes through under any specification of the efficiency distributions.

${ }^{11}$ Equation (32) shows that, if production technologies are not Cobb-Douglas, TFP correlations could rise with trade intensity if an increase in trade shifts countries' output shares toward sectors that are more correlated. 
such a decrease in the share of goods purchased domestically. In this sense, the welfare-based productivity measure reflects transmission of productivity shocks across countries.

\section{Vertical Specialization and Trade}

Before proceeding to our numerical experiments, we review some measures of vertical specialization in the data, and show how to construct corresponding measures in the model.

A commonly cited measure of vertical specialization is the one in Hummels, Ishii \& Yi (2001). The authors define an index of vertical specialization for a given sector as the ratio of imported inputs to gross output. To construct an economywide measure of vertical specialization, they aggregate this index across sectors, weighted by each sector's share of exports, to capture the degree to which imported inputs are important in exporting sectors. Their measure for country $i$ is then given by:

$$
\mathrm{VS}^{i}=\frac{\sum_{v} \frac{I I_{v}^{i}}{Z_{v}^{i}} \operatorname{Exports}_{v}^{i}}{\sum_{v} \operatorname{Exports}_{v}^{i}}
$$

where $v$ denotes a sector, $I I_{v}^{i}$ denotes imported intermediates in sector $v$, and $Z_{v}^{i}$ denotes gross output in sector $v$. When the exports of a sector are zero, that sector does not affect the index. When imported intermediate inputs in a sector are zero, that sector does not add to the numerator of the index. Countries are more vertically specialized if they export more in sectors that use imported intermediates intensively. Using Input-Output tables Hummels et al. (2001) report increasing vertical specialization in international trade evaluated using this index; some numbers taken from their paper are illustrated in the columns labelled "VS index" in Table 1. 


\section{TABLE 1 ABOUT HERE.}

In our model we do not explicitly map the continuum of goods into a sectoral categorization. For the purposes of constructing a measure of vertical specialization comparable to the above index, we can think of all the goods as being assigned to one sector in the data. ${ }^{12}$ The share of intermediates in gross output for all the second stage goods is $\eta$ while the share of the value of imported intermediates out of the total value of intermediates is $\lambda_{1 t}^{i j}$. Therefore, in our model, the analogue of the index in Hummels et al. (2001) is given by:

$$
\mathrm{VS}^{i}=\frac{\eta \lambda_{1 t}^{j i} \frac{Z_{2}^{i}}{Z_{2}^{i}+Z_{1}^{i}} E_{2}^{i}}{E_{1}^{i}+E_{2}^{i}}
$$

where $Z_{s}^{i}, s=1,2$ denote gross output in each stage and $E_{s}^{i}$ denotes country $i$ 's exports from in each stage.

Additionally, we can use input-output tables to directly construct measures in the data analogous to the shares of intermediate and final expenditures spend by a country on domestic goods, the $\lambda_{1}^{i i}$ and $\lambda_{2}^{i i}$. Table 1 also shows these statistics. As trade has increased significantly over time in these countries (a decrease in the fraction spent on domestic goods), both the shares of imported intermediate and final goods have increased. However, the imported share of intermediate inputs increased more than the imported share of final goods.

In the next section, we evaluate the ability of versions of our model with and without vertical specialization to generate higher synchronization of business cycles between countries that have higher trade intensity.

\footnotetext{
${ }^{12}$ Alternatively, a random assignment of subsets of goods along the continuum from each stage into sectors would give the same result.
} 


\section{Numerical Experiments}

We set several parameters to standard values in the international business cycle literature. We interpret one model period as one quarter, and set the discount factor $\beta=0.99$ so that the steady state real interest rate is $4 \%$ per year. We set $\alpha$ to 0.3 , so $30 \%$ of value added is paid to capital. The depreciation rate $\delta$ is set to $2.5 \%$ per period. The utility parameter $\mu$ is set to 0.34 , so that about $1 / 3$ of the total time endowment is supplied as labor in the steady state. We set the share of tradeable output in GDP to match the share of nontradeable expenditures in the model to the share of final expenditures on services in US input-output tables, giving $\gamma=.3$.

We assume that the technology shocks are equal across sectors within a country, $A_{1 t}^{i}=$ $A_{2 t}^{i}=A_{N t}^{i} \equiv A_{t}^{i}$, and that each country's aggregate technology follows an $\mathrm{AR}(1)$ process in $\operatorname{logs}, \log A_{t+1}^{i}=\rho \log A_{t}^{i}+\varepsilon_{t+1}^{i}$, for $i=1,2$, where $\varepsilon_{t}^{i}$ is a mean-zero normally distributed i.i.d. innovation with standard deviation $\sigma_{\varepsilon}$. We set $\rho=0.9$ and $\sigma_{\varepsilon}=0.01$. Both values are close to those used, for example, by Backus et al. (1994), and generate average autocorrelation and standard deviation of HP-filtered TFP in our benchmark experiments of 0.59 and 0.017 , respectively. Notably, we do not build any correlation into the shocks to technology across countries or across sectors, so that we isolate the degree to which our model endogenously generates cross-country correlation in measured real GDP. ${ }^{13}$

The model contains two parameters related to the elasticity of substitution between domestic and foreign goods. As in Eaton \& Kortum (2002), the role of the parameter $\sigma$ in determining the elasticity of trade is concealed by the role of $\theta$. While $\sigma$ governs substi-

\footnotetext{
${ }^{13}$ Adding positive correlation in the exogenous shocks would increase the levels of cross-country correlations, but does not affect their dependence on trade intensity.
} 
tutability in the intensive margin - within goods that are continuously traded - $\theta$ governs the heterogeneity across goods, and hence determines the extent to which the extensive margin of trade in new goods responds to variations in technology or trade costs. At the aggregate level, the elasticity of substitution between imported and domestic goods in our model is $\theta$. As Ruhl (2008) notes, measures of this aggregate elasticity in the data differ depending on the source of price variation: measures from time series data give small elasticities of the magnitude typically used in international business cycle models. On the other hand, estimates from cross-section data relating trade patterns to tariff and non-tariff barriers find elasticities that are much higher. Since the parameter $\theta$ governs the elasticity in response to both types of price variation in our model, we balance between the two measures by choosing a value of $\theta=3.6$ because it is the lowest of the three estimates from Eaton \& Kortum (2002). For the elasticity of substitution $\sigma$ that determines the substitution between different goods, we use the benchmark value of Backus et al. (1994) of $\sigma=1.5$, which is consistent with estimates of the elasticity of substitution between foreign and domestic goods by SITC commodity groups. ${ }^{14}$

The parameter $\eta$ determines the share of gross output in final goods paid to intermediate inputs. We consider two versions of our model, a one-stage benchmark with $\eta=1$, and a version with vertical specialization, with $\eta=0.5$, which is approximately the ratio of intermediate inputs to gross output in US input-output tables.

In the experiments below, we choose the technology parameters $T_{s}^{i}$ and the trade $\operatorname{costs} \tau_{s}^{i j}$ to generate different steady state specialization and international trade patterns. We subse-

\footnotetext{
${ }^{14}$ Recent estimates by Broda \& Weinstein (2006) place the median value of this elastictity across all sectors to be 2.5 and the average value much higher than that. The model constrains us to set $\theta>\sigma-1$ but raising the elasticity does not substantially alter our results.
} 
quently look at the degree of business cycle comovement across these different patterns. ${ }^{15}$

\section{Results}

We look at various cross-country correlations of H-P filtered variables in different versions of the model. In addition to real GDP and TFP, we also look at the correlations between countries of welfare-based real income, $\tilde{Y}^{i}$; aggregate labor supply; real consumption expenditures at base period prices, $\mathcal{C}_{t}^{i}=\int p_{20}^{i}(\omega) c_{T t}^{i}(\omega) d \omega+P_{N 0}^{i} C_{N t}^{i}$; real investment expenditures at base period prices, $\mathcal{X}_{t}^{i}=\int p_{20}^{i}(\omega) x_{T t}^{i}(\omega) d \omega+P_{N 0}^{i} X_{N t}^{i}$; and real value added in different stages of production:

$$
\begin{aligned}
& \mathcal{Y}_{1 t}^{i}=\int_{\Omega_{1 t}^{i}} \tilde{q}_{10}^{i}(\omega) y_{1 t}^{i}(\omega) d \omega \\
& \mathcal{Y}_{2 t}^{i}=\int_{\Omega_{2 t}^{i}} \tilde{q}_{20}^{i}(\omega) y_{2 t}^{i}(\omega) d \omega-\int_{\Omega_{2 t}^{i}} \int p_{10}^{i}\left(\omega^{\prime}\right) m_{t}^{i}\left(\omega, \omega^{\prime}\right) d \omega^{\prime} d \omega
\end{aligned}
$$

In light of Proposition 2, we show the alternative income measure, $\tilde{Y}$, to get a sense of how large the effects of increases in trade and vertical specialization are on comovement, even though it does not appear in traditional national accounting statistics.

\section{TABLE 2 ABOUT HERE.}

We first look at a version of the model with no vertical specialization which we denote as the benchmark. The goal is to subsequently introduce different experiments where vertical specialization arises for different reasons and compare the properties of these versions of the model with the benchmark. The left half of Table 2 shows statistics for the benchmark

\footnotetext{
${ }^{15} \mathrm{In}$ an appendix available online, we perform sensitivity analysis with respect to the elasticity parameters $\theta$ and $\sigma$, and the correlation of shocks $\varepsilon_{t+1}^{i}$, and show that the nature of our main results do not change.
} 
model, with $\eta=1$, and with symmetric countries, so that $T_{s}^{1}=T_{s}^{2}$. When we vary trade costs to generate steady state trade to GDP ratios between $3 \%$ and $15 \%$, we see that the correlation of real GDP across countries increases very slightly, from .01 to .04. One way to compare this numbers to measures in the data is by looking at the implied slope of the GDP correlation - trade intensity relationship: the difference in GDP correlation over the difference in the log of the trade to GDP ratio. Kose \& Yi (2006) estimate this slope at 0.091 in cross-country data. The slope for our benchmark model is 0.019 , about one fifth of Kose and Yi's estimate. Our experiments are conducted for trade intensities exceeding those of the typical country pair in Kose and Yi's data, so this slope should be considered an upper bound on what our model can produce. Kose and Yi also show that a three-country extension of Backus et al. (1994) calibrated to match bilateral trade shares for select countries can account for at most about $11 \%$ of this slope (in their baseline calibration). Confirming Proposition 1, the correlation of TFP across countries is close to zero, and essentially does not rise with trade intensity. The correlations of labor, investment, and consumption rise across trade intensities, from .02 to .10 for labor and investment, and from .01 to .11 for consumption. In addition, consistent with Proposition 2, the correlations of the alternative measure of real income $\tilde{Y}$, and the corresponding productivity measure $\tilde{A}$, increase with trade intensity much more than that of real GDP. The implied slope of these correlations with trade intensity is 0.056 , nearly triple the real GDP slope.

The right half of Table 2 shows our model with vertical specialization, in three cases in which the trade $\operatorname{costs} \tau_{s}^{i j}$ and technology parameters $T_{s}^{i}$ are the same across countries and across stages of production. As trade intensity increases in this model from $3 \%$ to $15 \%$, the 
steady state vertical specialization measure increases as well, from $0.26 \%$ to $1.32 \%{ }^{16}$ The patterns of cross country correlations are broadly similar to the one-stage model, except that the increases are smaller as trade intensity rises. Even for the correlations of $\tilde{Y}$ and $\tilde{A}$, real income and its associated productivity measure, the increases across trade intensity are smaller than in the one stage benchmark. This result makes sense, given proposition 2, and the fact that technology shocks might change specialization to a different degree in each stage of production. With two trade shares, $\lambda_{1 t}^{i i}$ and $\lambda_{2 t}^{i i}$, there is another source of variation in $\tilde{A}$ compared to the one-stage benchmark. In fact, with symmetric countries, the presence of two stages of production actually reduces, rather than enhances the dependence of comovement on trade.

Another reason that correlations rise with trade intensity to a smaller degree in the model with vertical specialization is that our measure of trade intensity is a measure of the gross output of goods traded, not value added. As Kose \& Yi (2001) point out, for a given trade intensity, less value-added is traded in the model with vertical specialization than in the model without. If we instead vary transport costs so that the value-added of imports relative to GDP is $3 \%, 9 \%$, and $15 \%$, then the correlations of real GDP are .01, .02, and .03, respectively.

\section{TABLE 3 ABOUT HERE.}

In Table 3 we show statistics for two variations of our model with $15 \%$ trade intensity, in which trade costs differ across stages of production. The column labelled "Low VS"

\footnotetext{
${ }^{16}$ While the $\lambda_{1}^{i j}$ fractions in our model results come close to the data for, for example, the US (compare to $1-\lambda_{1}^{i i}$ in Table 1 ), the $V S$ measures our model predicts are much smaller than in the data. This suggests that sectoral differences that are emphasized by the $V S$ measure of Hummels et al. (2001) may be important.
} 
has relatively high trade costs for first stage goods, so that trade intensity in these goods is dampened, while the column labelled "High VS" has relatively low trade costs for first stage goods. The results indicate that a higher degree of vertical specialization does not significantly affect the business cycle correlations we consider if countries are symmetric.

\section{TABLE 4 ABOUT HERE.}

Finally, in Table 4 we consider a case in which countries are asymmetric: we choose the $T_{s}^{i}$ terms so that country 1 has a comparative advantage in the production of stage 1 goods, while country 2 has a comparative advantage in stage 2 goods, and both countries have the same steady state GDP. In the left column, labeled "low specialization", the degree of comparative advantage is smaller than in the right column, labeled "high specialization", so that the vertical specialization measure for country 2 is larger, and for country 1 is smaller, in the right column. We see again that most of the cross-country correlations change little across these cases. The exception is the correlation of real value added across countries in different stages: while the correlation of real value added in the sector in which each country specializes is only .02 in the low specialization case, this correlation increases to .13 in the high specialization case. The extent to which countries are negatively correlated in the sectors in which they do not have comparative advantage increases as well. The negative change slightly outweighs the positive change here, so that even though it applies to sectors that are small in each country, the overall effect is that the correlation of aggregate real GDP is similar under low specialization or high specialization.

In these results, we have shown that several versions of our model can generate moderate increases in business cycle comovement with increases in trade intensity. However, for the 
cases we have considered here, these increases are small, and the addition of vertical specialization does not contribute significantly to magnifying them. While asymmetric countries in our model clearly do display the tight links across sectors that vertical specialization implies, additional mechanisms would be needed to translate these links to aggregate real GDP and measured TFP. In the next section, we examine one such mechanism.

\section{An Extension with Imperfect Competition}

Having established that our model with perfect competition does not provide a link between trade and TFP correlations, we follow Bernard et al. (2003) by introducing in our model a sort of imperfect competition that breaks the link between prices and producers' efficiencies, and show that it has the potential to link trade intensity to correlations in measured TFP, as well as real GDP.

We modify the structure of our model as follows: in each country, there are a large number of potential producers of each good, and country $i$ 's $k$ 'th most efficient producer of good $\omega$ in stage $s$ has efficiency $z_{k s}^{i}(\omega)$. The lowest cost among producers in both countries of delivering good $\omega$ to country $j$ is then $p_{1 s t}^{j}(\omega)=\min \left\{q_{s t}^{i} \tau_{s}^{i j} / z_{1 s}^{i}(\omega): i=1,2\right\}$.

Under Bertrand competition, each good is sold in a country by the producer with the lowest-cost of selling there, but this producer charges a price equal to either the second best producer's marginal cost or a fixed markup over its own marginal cost, whichever is smaller. The second lowest cost is $p_{2 s t}^{j}(\omega)=\min _{2}\left\{q_{s t}^{i} \tau_{s}^{i j} / z_{k s}^{i}(\omega): i=1,2, k=1,2\right\}$, where $\min _{2}$ refers to the second smallest. Therefore, the price charged for good $\omega$ in country $j$ is

$$
p_{s t}^{j}(\omega)=\min \left\{p_{2 s t}^{j}(\omega), \bar{m} p_{1 s t}^{j}(\omega)\right\},
$$


where $\bar{m}=\sigma /(\sigma-1)$ is the monopolistic markup. In this model, we assume that $\sigma>1$, so that the monopolistic markup is positive.

The only relevant efficiencies for determining prices and production patterns are $z_{1 s}^{i}(\omega)$ and $z_{2 s}^{i}(\omega)$. We assume that these efficiencies are jointly distributed according to the analogue of the Fréchet distribution in Bernard et al. (2003): the joint probability that $z_{1 s}^{i}(\omega) \leq$ $z_{1}$ and $z_{2 s}^{i}(\omega) \leq z_{2}$, for $z_{2} \leq z_{1}$, is given by $F_{s}^{i}\left(z_{1}, z_{2}\right)=\left(1+T_{s}^{i}\left(z_{2}^{-\theta}-z_{1}^{-\theta}\right)\right) e^{-T_{s}^{i} z_{2}^{-\theta}}$.

The marginal distribution of $z_{1}$ is still given by (13), so the parameters $T_{s}^{i}$ and $\theta$ play the same role as in the previous setup. Following the derivations in Bernard et al. (2003), the CES price indices for each stage are:

$$
P_{s t}^{j}=\left[\left(1+\frac{(\sigma-1) \bar{m}^{\theta}}{\theta+1-\sigma}\right) \Gamma\left(\frac{2 \theta+1-\sigma}{\theta}\right)\right]^{1 /(1-\sigma)}\left(\Phi_{s t}^{j}\right)^{-1 / \theta}
$$

where $\Phi_{s t}^{j}$ and the trade shares $\lambda_{s t}^{i j}$ are defined in the same way as in (15) and (17).

Finally, the model with Bertrand competition differs in that producers earn profits, so consumers' budget constraints are modified to include profits and the market clearing conditions are modified. As Bernard et al. (2003) show, aggregate profits in each stage are a fraction $1 /(1+\theta)$ of total revenues, so that the market clearing conditions for each stage of tradable goods can be written:

$$
\begin{aligned}
& w_{t}^{i} L_{1 t}^{i}+r_{t}^{i} K_{1 t}^{i}=\frac{\theta}{1+\theta}\left(\lambda_{1 t}^{i i} P_{1 t}^{i}\left(M_{T t}^{i}+M_{N t}^{i}\right)+\lambda_{1 t}^{i j} P_{1 t}^{j}\left(M_{T t}^{j}+M_{N t}^{j}\right)\right) \\
& w_{t}^{i} L_{2 t}^{i}+r_{t}^{i} K_{2 t}^{i}=\eta \frac{\theta}{1+\theta}\left(\lambda_{2 t}^{i i} P_{2 t}^{i}\left(C_{T t}^{i}+X_{T t}^{i}\right)+\lambda_{2 t}^{i j} P_{2 t}^{i j}\left(C_{T t}^{j}+X_{T t}^{j}\right)\right) .
\end{aligned}
$$

In the case of Bertrand competition, efficiency does not map one-to-one to prices, as 
evident in (38). In light of the discussion in Section IV., this disconnection gives the model more potential to generate cross-country correlation in measured TFP and real GDP. ${ }^{17}$ Table 5 displays the analogues of the results in Table 2 for this extension of the model. As we go from $3 \%$ to $15 \%$ trade intensity, the correlation of real GDP increases from .01 to .06 in the one stage benchmark, and from .04 to .09 in the vertical specialization model. The slope of the GDP correlation in the vertical specialization model is 0.031, about one third of the slope estimated in the data in Kose \& Yi (2006). This increase is also seen in the correlation of measured TFP, which increases from .02 to to .06 in the one stage model, and from .04 to .10 in the vertical model. The latter result was qualitatively missing in the model with perfect competition. In the vertical specialization model with imperfect competition, the implied slope of the TFP correlation and trade relationship is 0.037 , about $40 \%$ of the slope that Kose \& Yi (2006) estimate in the data, which is 0.089 . Thus, the model with imperfect competition, through its effects on the measurement of real GDP, qualitatively changes the way that measured TFP depends on trade in our model, and has the potential to quantitatively change the relationship between trade intensity and GDP correlations. An extension of this setup to a model with more than two countries, calibrated to match bilateral trade shares, would be needed to provide a better quantitative evaluation of this mechanism's ability, combined with endogenous specialization, to solve the trade-comovement puzzle.

TABLE 5 ABOUT HERE.

\footnotetext{
${ }^{17}$ With imperfect competition, the expressions we derived above for real GDP are no longer valid, and analogous expressions are much more intractable. To compute aggregate statistics, we draw efficiencies for one hundred thousand goods, compute the relevant variables for producers of each good every period, and calculate aggregates at base-period prices as sample averages.
} 


\section{Conclusion}

We have developed a model vertical specialization in international trade in a setting with aggregate fluctuations. We asked whether this framework can account for the trade comovement puzzle identified by Kose \& Yi (2001) and (2006). While the framework we develop does not resolve the puzzle, our work helps to take important steps in understanding the reasons behind its persistence under different modeling frameworks: we prove that with perfect competition, measured TFP does not depend on trade or vertical specialization intensity. While vertical specialization as we have specified it provides an intuitive reason for countries that trade more to be more correlated, additional mechanisms are needed to account for the extent to which this channel affects the behavior of measured business cycle statistics. Our preliminary results from a model with variable markups indicate that this feature, combined with vertical specialization, is a promising avenue for further exploration to link trade and TFP fluctuations. 


\begin{tabular}{|l|c|c|c|c|c|c|c|c|}
\hline & Year & $V S$ index & $\lambda_{1}^{i i}$ & $\lambda_{2}^{i i}$ & Year. & $V S$ index & $\lambda_{1}^{i i}$ & $\lambda_{2}^{i i}$ \\
\hline Canada & 1971 & .20 & .77 & .71 & 1990 & .27 & .70 & .57 \\
\hline France & 1972 & .18 & .81 & .86 & 1990 & .24 & .70 & .72 \\
\hline Germany & 1978 & .18 & .79 & .81 & 1990 & .20 & .75 & .73 \\
\hline Japan & 1970 & .18 & .90 & .95 & 1990 & .11 & .89 & .91 \\
\hline United Kingdom & 1979 & .25 & .74 & .75 & 1990 & .26 & .64 & .62 \\
\hline United States & 1972 & .06 & .94 & .93 & 1990 & .11 & .88 & .81 \\
\hline
\end{tabular}

Table 1: Vertical Specialization Measures from Hummels et al. (2001) and domestic expenditure shares for intermediate and final goods from OECD Input-Output Tables

\begin{tabular}{|l|l|l|l|l|l|l|}
\hline & \multicolumn{3}{|c|}{ Benchmark $(\eta=1)$} & \multicolumn{3}{c|}{ Vert. Spec. $(\eta=.5)$} \\
\hline variable & trade/GDP & trade/GDP \\
\hline & $3 \%$ & $9 \%$ & $15 \%$ & $3 \%$ & $9 \%$ & $15 \%$ \\
\hline $\operatorname{corr}\left(\mathcal{Y}^{1}, \mathcal{Y}^{2}\right)$ & .01 & .02 & .04 & .01 & .01 & .02 \\
\hline $\operatorname{corr}\left(\mathcal{A}^{1}, \mathcal{A}^{2}\right)$ & .00 & .00 & .01 & .01 & .00 & -.01 \\
\hline $\operatorname{corr}\left(L^{1}, L^{2}\right)$ & .02 & .05 & .10 & .02 & .04 & .07 \\
\hline $\operatorname{corr}\left(\mathcal{X}^{1}, \mathcal{X}^{2}\right)$ & .02 & .05 & .10 & .02 & .04 & .06 \\
\hline $\operatorname{corr}\left(\mathcal{C}^{1}, \mathcal{C}^{2}\right)$ & .01 & .03 & .11 & .01 & .02 & .03 \\
\hline $\operatorname{corr}\left(\tilde{Y}^{1}, \tilde{Y}^{2}\right)$ & .02 & .06 & .11 & .02 & .04 & .07 \\
\hline $\operatorname{corr}\left(\tilde{A}^{1}, \tilde{A}^{2}\right)$ & .02 & .06 & .11 & .02 & .04 & .07 \\
\hline$\left(\lambda_{1}^{i j}, \lambda_{2}^{i j}\right)$ & $(-, .10)$ & $(-, .30)$ & $(-, .50)$ & $(.04, .04)$ & $(.11, .11)$ & $(.19, .19)$ \\
\hline $\operatorname{VS}$ index $(\%)$ & - & - & - & .26 & .79 & 1.32 \\
\hline
\end{tabular}

Table 2: Model business cycle correlations (see text for variable definitions). 


\begin{tabular}{|l|l|l|}
\hline & $\eta=.5$, High VS & $\eta=.5$, Low VS \\
\hline variable & trade/GDP & trade/GDP \\
\hline & $15 \%$ & $15 \%$ \\
\hline $\operatorname{corr}\left(\mathcal{Y}^{1}, \mathcal{Y}^{2}\right)$ & .03 & .02 \\
\hline $\operatorname{corr}\left(\mathcal{A}^{1}, \mathcal{A}^{2}\right)$ & .00 & .00 \\
\hline $\operatorname{corr}\left(L^{1}, L^{2}\right)$ & .08 & .06 \\
\hline $\operatorname{corr}\left(\mathcal{X}^{1}, \mathcal{X}^{2}\right)$ & .08 & .06 \\
\hline $\operatorname{corr}\left(\mathcal{C}^{1}, \mathcal{C}^{2}\right)$ & .06 & .04 \\
\hline $\operatorname{corr}\left(\tilde{Y}^{1}, \tilde{Y}^{2}\right)$ & .09 & .07 \\
\hline $\operatorname{corr}\left(\tilde{A}^{1}, \tilde{A}^{2}\right)$ & .09 & .07 \\
\hline $\operatorname{corr}\left(\mathcal{Y}_{1}^{1}, \mathcal{Y}_{2}^{2}\right)$ & .00 & -.01 \\
\hline$\left(\lambda_{1}^{i j}, \lambda_{2}^{i j}\right)$ & $(.09, .35)$ & $(.25, .09)$ \\
\hline $\operatorname{VS}$ index $(\%)$ & 1.18 & .83 \\
\hline
\end{tabular}

Table 3: Model correlations for high and low vertical specialization cases (See text for variable definitions) 


\begin{tabular}{|l|l|l|}
\hline & $\eta=.5$, Low specialization & $\eta=.5$, High specialization \\
\hline variable & trade/GDP & trade/GDP \\
\hline & $15 \%$ & $15 \%$ \\
\hline $\operatorname{corr}\left(\mathcal{Y}^{1}, \mathcal{Y}^{2}\right)$ & .02 & .04 \\
\hline $\operatorname{corr}\left(\mathcal{A}^{1}, \mathcal{A}^{2}\right)$ & .00 & .02 \\
\hline $\operatorname{corr}\left(L^{1}, L^{2}\right)$ & .07 & .08 \\
\hline $\operatorname{corr}\left(\mathcal{X}^{1}, \mathcal{X}^{2}\right)$ & .06 & .07 \\
\hline $\operatorname{corr}\left(\mathcal{C}^{1}, \mathcal{C}^{2}\right)$ & .05 & .09 \\
\hline $\operatorname{corr}\left(\tilde{Y}^{1}, \tilde{Y}^{2}\right)$ & .07 & .08 \\
\hline $\operatorname{corr}\left(\tilde{A}^{1}, \tilde{A}^{2}\right)$ & .07 & .08 \\
\hline $\operatorname{corr}\left(\mathcal{Y}_{1}^{1}, \mathcal{Y}_{2}^{2}\right)$ & .02 & .13 \\
\hline $\operatorname{corr}\left(\mathcal{Y}_{2}^{1}, \mathcal{Y}_{1}^{2}\right)$ & -.06 & -.19 \\
\hline$\left(\lambda_{1}^{21}, \lambda_{2}^{21}\right)$ & $(.17, .23)$ & $(.08, .38)$ \\
\hline$\left(\lambda_{1}^{12}, \lambda_{2}^{12}\right)$ & $(.21, .15)$ & $(.25, .05)$ \\
\hline$V S^{1}$ index $(\%)$ & .87 & .10 \\
\hline$V S^{2}$ index $(\%)$ & 1.89 & 4.41 \\
\hline
\end{tabular}

Table 4: Model correlations with asymmetric countries. Country 1 has comparative advantage in first stage (See text for variable definitions)

\begin{tabular}{|l|l|l|l|l|l|l|}
\hline & \multicolumn{3}{|c|}{ Benchmark $(\eta=1)$} & \multicolumn{3}{|c|}{ Vert. Spec. $(\eta=.5)$} \\
\hline variable & \multicolumn{3}{|c|}{ trade/GDP } & \multicolumn{3}{|c|}{ trade/GDP } \\
\hline & $3 \%$ & $9 \%$ & $15 \%$ & $3 \%$ & $9 \%$ & $15 \%$ \\
\hline $\operatorname{corr}\left(\mathcal{Y}^{1}, \mathcal{Y}^{2}\right)$ & .01 & .04 & .06 & .04 & .06 & .09 \\
\hline $\operatorname{corr}\left(\mathcal{A}^{1}, \mathcal{A}^{2}\right)$ & .02 & .04 & .06 & .04 & .07 & .10 \\
\hline $\operatorname{corr}\left(L^{1}, L^{2}\right)$ & .01 & .03 & .06 & .03 & .05 & .07 \\
\hline $\operatorname{corr}\left(\mathcal{X}^{1}, \mathcal{X}^{2}\right)$ & .01 & .03 & .06 & .03 & .05 & .07 \\
\hline $\operatorname{corr}\left(\mathcal{C}^{1}, \mathcal{C}^{2}\right)$ & .02 & .05 & .08 & .04 & .06 & .09 \\
\hline $\operatorname{corr}\left(\tilde{Y}^{1}, \tilde{Y}^{2}\right)$ & .01 & .03 & .07 & .03 & .05 & .07 \\
\hline $\operatorname{corr}\left(\tilde{A}^{1}, \tilde{A}^{2}\right)$ & .01 & .03 & .07 & .03 & .05 & .07 \\
\hline
\end{tabular}

Table 5: Model business cycle correlations, imperfect competition case (see text for variable definitions). 


\section{A Appendix}

Sketch of proof of Proposition 1. More details for the proofs are available in an online appendix in the authors' websites. The goal of this proof is to compute a first order approximation of the relationship $\mathcal{Y}_{t}^{i}=\mathcal{Z}_{t}^{i}-\mathcal{I}_{t}^{i}$. We make use of the approximation $g\left(x_{t}\right) \approx$ $g^{\prime}(x) x \hat{x}_{t}$, where $\hat{x}_{t}=\log \left(x_{t}\right)-\log (x)$. Variables without a time subscript refer to the steady state (base period) value. The approximation can be written as $\mathcal{Y}^{i} \hat{\mathcal{Y}}_{t}^{i}=\mathcal{Z}^{i} \hat{\mathcal{Z}}_{t}^{i}-\mathcal{I}^{i} \hat{\mathcal{I}}_{t}^{i}$ where

$$
\begin{gathered}
\mathcal{Z}^{i} \hat{\mathcal{Z}}_{t}^{i}=\left(w^{i} L_{1}^{i}+r^{i} K_{1}^{i}\right) \hat{A}_{1 t}^{i}+\left(w^{i} L_{2}^{i}+r^{i} K_{2}^{i}+P_{1}^{i} M_{T}^{i}\right) \hat{A}_{2 t}^{i}+\left(w^{i} L_{N}^{i}+r^{i} K_{N}^{i}+P_{1}^{i} M_{N}^{i}\right) \hat{A}_{N t}^{i} \\
+w^{i} L^{i} \hat{L}_{t}^{i}+r^{i} K^{i} \hat{K}_{t}^{i}+P_{1}^{i} M_{T}^{i} \hat{M}_{T t}^{i}+P_{1}^{i} M_{N}^{i} \hat{M}_{N t}^{i}, \\
\mathcal{I}^{i} \hat{\mathcal{I}}_{t}^{i}=P_{1}^{i} M_{T}^{i} \hat{M}_{T t}^{i}+P_{1}^{i} M_{N}^{i} \hat{M}_{N t}^{i} .
\end{gathered}
$$

The derivations are lengthy, but some intuition is provided in the text and the technical details are in an online appendix. By using the fact that in the steady state, $\mathcal{Y}^{i}=Y^{i}$, along with $\left(w^{i} L_{1}^{i}+r^{i} K_{1}^{i}\right) / Y^{i}=1-\eta,\left(w^{i} L_{2}^{i}+r^{i} K_{2}^{i}+P_{1}^{i} M_{T}^{i}\right) / Y^{i}=\gamma$, and $\left(w^{i} L_{N}^{i}+r^{i} K_{N}^{i}+P_{1}^{i} M_{N}^{i}\right) / Y^{i}=$ $1-\gamma$, we arrive at the conclusion that

$$
\hat{\mathcal{Y}}_{t}^{i}=(1-\eta) \hat{A}_{1 t}^{i}+\gamma \hat{A}_{2 t}^{i}+(1-\gamma) \hat{A}_{N t}^{i}+(1-\alpha) \hat{L}_{t}^{i}+\alpha \hat{K}_{t}^{i}
$$

The definition of $\hat{\mathcal{A}}_{t}^{i}$ directly implies equation (32).

Sketch of proof of Proposition 2. The proof requires substituting equation (16) with (17) and equation (20) into the expression for real income, (33), as well as using the fact that the aggregate capital/ labor ratio is $K_{t}^{i} / L_{t}^{i}=\alpha w_{t}^{i} /\left((1-\alpha) r_{t}^{i}\right)$. 


\section{References}

Backus, D., Kehoe, P. \& Kydland, F. (1994), 'Dynamics of the trade balance and the terms of trade: The j-curve?', The American Economic Review 84(1), 84-103.

Baxter, M. \& Kouparitsas, M. (2005), 'Determinants of business cycle comovement: A robust analysis', Journal of Monetary Economics 52(1), 113-157.

Bergin, P. R., Feenstra, R. C. \& Hanson, G. H. (2007), 'Outsourcing and volatility', NBER Working Paper 13144 .

Bernard, A. B., Eaton, J., Jensen, B. \& Kortum, S. (2003), 'Plants and productivity in international trade', The American Economic Review 93(4), 1268-1290.

Broda, C. \& Weinstein, D. (2006), 'Globalization and the gains from variety', Quarterly Journal of Economics 121(2), 541-585.

Burstein, A. C., Kurz, J. \& Tesar, L. (2008), 'Trade, production sharing, and the international transmission of business cycles', Journal of Monetary Economics 55(4), 775-795.

Clark, T. E. \& Van Wincoop, E. (2001), 'Borders and business cycles', Journal of Intermational Economics 55(1), 59-85.

Di Giovanni, J. \& Levchenko, A. A. (2008), 'Putting the parts together: Trade, vertical linkages, and business cycle comovement', forthcoming, American Economic Journal: Macroeconomics .

Drozd, L. A. \& Nosal, J. (2008), 'Long-run elasticity of trade and the trade-comovement puzzle', mimeo, University of Wisconsin-Madison . 
Eaton, J. \& Kortum, S. (2002), 'Technology, geography and trade', Econometrica 70(5), 1741-1779.

Frankel, J. A. \& Rose, A. K. (1998), 'The endogeneity of the optimum currency area criteria', The Economic Journal 108(449), 1009-1025.

Ghironi, F. \& Melitz, M. (2005), 'International trade and macroeconomic dynamics with heterogeneous firms', Quarterly Journal of Economics 120(3), 865-915.

Gibson, M. J. (2006), 'Trade liberalization, reallocation, and productivity', mimeo, Washington State University .

Heathcote, J. \& Perri, F. (2002), 'Financial autarky and international business cycles', Journal of Monetary Economics 49(3), 601-627.

Huang, K. X. D. \& Liu, Z. (2007), 'Business cycles with staggered prices and international trade in intermediate inputs', Journal of Monetary Economics 54(4), 1271-1289.

Hulten, C. R. (1978), 'Growth accounting with intermediate inputs', The Review of Economic Studies 45(3), 511-518.

Hummels, D., Ishii, J. \& Yi, K.-M. (2001), 'The nature and growth of vertical specialization in world trade', Journal of International Economics 54(1), 75-96.

Kehoe, T. J. \& Ruhl, K. J. (2008), 'Are shocks to the terms of trade shocks to productivity?', Review of Economic Dynamics 11(4), 804-819. 
Kose, M. A. \& Yi, K.-M. (2001), 'International trade and business cycles: Is vertical specialization the missing link?', The American Economic Review Papers and Proceedings 371-375(2), 91.

Kose, M. A. \& Yi, K.-M. (2006), 'Can the standard international business cycle model explain the relation between trade and comovement', Journal of International Economics 68(2), 267-295.

Krugman, P. \& Venables, A. J. (1995), 'Globalization and the inequality of nations', Quarterly Journal of Economics 110(4), 857-880.

Naknoi, K. (2008), 'Real exchange rate fluctuations,endogenous tradability and exchange rate regimes', Journal of Monetary Economics 55(3), 645-663.

Ng, E. C. Y. (2007), 'Vertical specialization, intra-industry trade, and business cycle comovement', mimeo, Wilfrid Laurier University .

Yi, K.-M. (2003), 'Can vertical specialization explain the growth of world trade?', Journal of Political Economy 111(1), 52-102.

Yi, K.-M. (2009), 'Vertical specialization and the border effect puzzle', forthcoming, American Economic Review . 


\section{B Appendix}

Model expressions for real GDP

\section{Aggregate Gross Output}

We use equation (29) and the fact that the value of gross output of each good evaluated at current prices is equal to the value of payments to inputs to write:

$$
\begin{aligned}
\mathcal{Z}_{t}^{i}= & \frac{P_{N 0}^{i}}{P_{N t}^{i}}\left(w_{t}^{i} L_{N t}^{i}+r_{t}^{i} K_{N t}^{i}+P_{1 t}^{i} M_{N t}^{i}\right)+\int_{\Omega_{1 t}^{i}} \frac{\tilde{q}_{10}^{i}(\omega)}{q_{1 t}^{i}(\omega)}\left(w_{t}^{i} \ell_{1 t}^{i}(\omega)+r_{t}^{i} k_{1 t}^{i}(\omega)\right) d \omega \\
& +\int_{\Omega_{2 t}^{i}} \frac{\tilde{q}_{20}^{i}(\omega)}{q_{2 t}^{i}(\omega)}\left(w_{t}^{i} \ell_{2 t}^{i}(\omega)+r_{t}^{i} k_{2 t}^{i}(\omega)+P_{1 t}^{i} M_{T t}^{i}(\omega)\right) d \omega
\end{aligned}
$$

Each set of the form $\Omega_{s t}^{i}$ consists of two parts: those goods that were produced by country $i$ in period $0, \Omega_{s t}^{i} \cap \Omega_{s 0}^{i}$, and those that were imported, $\Omega_{s t}^{i} \cap \Omega_{s 0}^{j i}$. Imposing this partition and rearranging terms gives:

$$
\begin{aligned}
\mathcal{Z}_{t}^{i}= & \frac{P_{N 0}^{i}}{P_{N t}^{i}}\left(w_{t}^{i} L_{N t}^{i}+r_{t}^{i} K_{N t}^{i}+P_{1 t}^{i} M_{N t}^{i}\right)+\int_{\Omega_{1 t}^{i}} \frac{q_{10}^{i}(\omega)}{q_{1 t}^{i}(\omega)}\left(w_{t}^{i} \ell_{1 t}^{i}(\omega)+r_{t}^{i} k_{1 t}^{i}(\omega)\right) d \omega \\
& +\int_{\Omega_{1 t}^{i} \cap \Omega_{10}^{j i}} \frac{q_{10}^{j}(\omega)-q_{10}^{i}(\omega)}{q_{1 t}^{i}(\omega)}\left(w_{t}^{i} \ell_{1 t}^{i}(\omega)+r_{t}^{i} k_{1 t}^{i}(\omega)\right) d \omega \\
& +\int_{\Omega_{2 t}^{i}} \frac{q_{20}^{i}(\omega)}{q_{2 t}^{i}(\omega)}\left(w_{t}^{i} \ell_{2 t}^{i}(\omega)+r_{t}^{i} k_{2 t}^{i}(\omega)+P_{1 t}^{i} M_{T t}^{i}(\omega)\right) d \omega \\
& +\int_{\Omega_{2 t}^{i} \cap \Omega_{20}^{j i}} \frac{q_{20}^{j}(\omega)-q_{20}^{i}(\omega)}{q_{2 t}^{i}(\omega)}\left(w_{t}^{i} \ell_{2 t}^{i}(\omega)+r_{t}^{i} k_{2 t}^{i}(\omega)+P_{1 t}^{i} M_{T t}^{i}(\omega)\right) d \omega
\end{aligned}
$$

Using $q_{s t}^{i}(\omega)=q_{s t}^{i} / z_{s}^{i}(\omega)$ the $z_{s}^{i}(\omega)$ terms in $\tilde{q}_{s 0}^{i}(\omega) / q_{s t}^{i}(\omega)$ cancel out for goods in all of $\Omega_{s t}^{i}$, so that the input demands can be aggregated across sectors using the relationships in 
equations (6) and (23): ${ }^{18}$

$$
\begin{aligned}
\mathcal{Z}_{t}^{i}= & \frac{P_{N 0}^{i}}{P_{N t}^{i}}\left(w_{t}^{i} L_{N t}^{i}+r_{t}^{i} K_{N t}^{i}+P_{1 t}^{i} M_{N t}^{i}\right)+\frac{q_{10}^{i}}{q_{1 t}^{i}}\left(w_{t}^{i} L_{1 t}^{i}+r_{t}^{i} K_{1 t}^{i}\right) \\
& +\frac{q_{20}^{i}}{q_{2 t}^{i}}\left(w_{t}^{i} L_{2 t}^{i}+r_{t}^{i} K_{2 t}^{i}+P_{1 t}^{i} M_{T t}^{i}\right) \\
& +\int_{\Omega_{1 t}^{i} \cap \Omega_{10}^{j i}} \frac{q_{10}^{j} z_{1}^{j}(\omega)-q_{10}^{i} z_{1}^{i}(\omega)}{q_{1 t}^{i} z_{1}^{i}(\omega)}\left(w_{t}^{i} \ell_{1 t}^{i}(\omega)+r_{t}^{i} k_{1 t}^{i}(\omega)\right) d \omega \\
& +\int_{\Omega_{2 t}^{i} \cap \Omega_{20}^{j i}} \frac{q_{20}^{j} z_{2}^{j}(\omega)-q_{20}^{i} z_{2}^{i}(\omega)}{q_{2 t}^{i} z_{2}^{i}(\omega)}\left(w_{t}^{i} \ell_{2 t}^{i}(\omega)+r_{t}^{i} k_{2 t}^{i}(\omega)+P_{1 t}^{i} M_{T t}^{i}(\omega)\right) d \omega .
\end{aligned}
$$

Now, the sets $\Omega_{s t}^{i} \cap \Omega_{s 0}^{j i}$ are defined by:

$$
\Omega_{s t}^{i} \cap \Omega_{s 0}^{j i}=\left\{\omega: q_{s t}^{i i} / q_{s t}^{j i} \leq z_{s}^{i}(\omega) / z_{s}^{j}(\omega) \leq q_{s 0}^{i i} / q_{s 0}^{j i}\right\}
$$

so that, changing the variable of integration from $\omega$ to pairs of $z_{s}^{i}, z_{s}^{j}$, the two integral terms in (A.1) can be written

$$
\Xi_{1 t}=\int_{0}^{\infty} \int_{z_{1}^{j} q_{1 t}^{i i} / q_{1 t}^{j i}}^{z_{1}^{j} q_{10}^{i i} / q_{10}^{j i}} \frac{q_{10}^{j} z_{1}^{j}-q_{10}^{i} z_{1}^{i}}{q_{1 t}^{i} z_{1}^{i}}\left(w_{t}^{i} \ell_{1 t}^{i}\left(z_{1}^{i}\right)+r_{t}^{i} k_{1 t}^{i}\left(z_{1}^{i}\right)\right) d F_{1}^{i}\left(z_{1}^{i}\right) d F_{1}^{j}\left(z_{1}^{j}\right)
$$

and

$$
\Xi_{2 t}=\int_{0}^{\infty} \int_{z_{2}^{j} q_{2 t}^{i i} / q_{2 t}^{j i}}^{z_{2}^{j} q_{20}^{i i} / q_{20}^{j i}} \frac{q_{20}^{j} z_{2}^{j}-q_{20}^{i} z_{2}^{i}}{q_{2 t}^{i} z_{2}^{i}}\left(w_{t}^{i} \ell_{2 t}^{i}\left(z_{2}^{i}\right)+r_{t}^{i} k_{2 t}^{i}\left(z_{2}^{i}\right)+P_{1 t}^{i} M_{T t}^{i}\left(z_{2}^{i}\right)\right) d F_{2}^{i}\left(z_{2}^{i}\right) d F_{2}^{j}\left(z_{2}^{j}\right)
$$

\footnotetext{
${ }^{18}$ The difference between (A.1) and the expression for gross output under the alternative base-period price rule is that the last two terms in (A.1) would be zero. As shown in the next subsection, these two terms are zero to a first order approximation.
} 


\section{Aggregate Expenditures on Intermediate Inputs}

In equation (30), we need to split up the range of goods purchased by country $i$ depending on the pattern of specialization both in the current period, and in the base period. We need to know from which country each good was bought in each period, to determine the base period price and the current period quantity purchased. Let $\Omega_{1 t}^{j i}$ denote the set of goods that country $i$ purchases from country $j$ in period $t$. Then, for example, the set of goods which country $i$ buys from home in period $t$ but imported in period 0 is $\Omega_{1 t}^{i i} \cap \Omega_{10}^{j i}$, so (30) can be written:

$$
\begin{aligned}
\mathcal{I}_{t}^{i}= & \int_{\Omega_{2 t}^{i}}\left(\int_{\Omega_{1 t}^{i i} \cap \Omega_{10}^{i i}} p_{10}^{i}\left(\omega^{\prime}\right) m_{t}^{i}\left(\omega, \omega^{\prime}\right) d \omega^{\prime}+\int_{\Omega_{1 t}^{i i} \cap \Omega_{10}^{j i}} p_{10}^{i}\left(\omega^{\prime}\right) m_{t}^{i}\left(\omega, \omega^{\prime}\right) d \omega^{\prime}\right. \\
& \left.+\int_{\Omega_{1 t}^{j i} \cap \Omega_{10}^{i i}} p_{10}^{i}\left(\omega^{\prime}\right) m_{t}^{i}\left(\omega, \omega^{\prime}\right) d \omega^{\prime}+\int_{\Omega_{1 t}^{j i} \cap \Omega_{10}^{j i}} p_{10}^{i}\left(\omega^{\prime}\right) m_{t}^{i}\left(\omega, \omega^{\prime}\right) d \omega^{\prime}\right) d \omega \\
& +\int_{\Omega_{1 t}^{i i} \cap \Omega_{10}^{i i}} p_{10}^{i}(\omega) m_{N t}^{i}(\omega) d \omega+\int_{\Omega_{1 t}^{i i} \cap \Omega_{10}^{j i}} p_{10}^{i}(\omega) m_{N t}^{i}(\omega) d \omega \\
& +\int_{\Omega_{1 t}^{j i} \cap \Omega_{10}^{i i}} p_{10}^{i}(\omega) m_{N t}^{i}(\omega) d \omega+\int_{\Omega_{1 t}^{j i} \cap \Omega_{10}^{j i}} p_{10}^{i}(\omega) m_{N t}^{i}(\omega) d \omega .
\end{aligned}
$$

We use the definitions of prices from (2) and (4) and the CES demand function for each good to write:

$$
\begin{aligned}
\mathcal{I}_{t}^{i}= & \left(\frac{q_{1 t}^{i i}}{P_{1 t}^{i}}\right)^{-\sigma}\left(M_{T t}^{i}+M_{N t}^{i}\right)\left(q_{10}^{i i} \int_{\Omega_{1 t}^{i i} \cap \Omega_{10}^{i i}} z_{1}^{i}(\omega)^{\sigma-1} d \omega+q_{10}^{j i} \int_{\Omega_{1 t}^{i i} \cap \Omega_{10}^{j i}} \frac{z_{1}^{i}(\omega)^{\sigma}}{z_{1}^{j}(\omega)} d \omega\right) \text { (A.4) } \\
& +\left(\frac{q_{1 t}^{j i}}{P_{1 t}^{i}}\right)^{-\sigma}\left(M_{T t}^{i}+M_{N t}^{i}\right)\left(q_{10}^{i i} \int_{\Omega_{1 t}^{j i} \cap \Omega_{10}^{i i}} \frac{z_{1}^{j}(\omega)^{\sigma}}{z_{1}^{i}(\omega)} d \omega+q_{10}^{j i} \int_{\Omega_{1 t}^{j i} \cap \Omega_{10}^{j i}} z_{1}^{j}(\omega)^{\sigma-1} d \omega\right) .
\end{aligned}
$$


Next, we use the fact that, for example, goods $\omega$ in $\Omega_{1 t}^{i i} \cap \Omega_{10}^{i i}$, are goods for which country $i$ has comparative advantage in both periods 0 and $t$ :

$$
\Omega_{1 t}^{i i} \cap \Omega_{10}^{i i}=\left\{\omega: z_{1}^{i}(\omega) / z_{1}^{j}(\omega) \geq \max \left\{q_{1 t}^{i i} / q_{1 t}^{j i}, q_{10}^{i i} / q_{10}^{j i}\right\}\right\}
$$

The other sets are analogously defined by

$$
\begin{gathered}
\Omega_{1 t}^{i i} \cap \Omega_{10}^{j i}=\left\{\omega: q_{1 t}^{i i} / q_{1 t}^{j i} \leq z_{1}^{i}(\omega) / z_{1}^{j}(\omega) \leq q_{10}^{i i} / q_{10}^{j i}\right\} . \\
\Omega_{1 t}^{j i} \cap \Omega_{10}^{i i}=\left\{\omega: q_{1 t}^{i i} / q_{1 t}^{j i} \geq z_{1}^{i}(\omega) / z_{1}^{j}(\omega) \geq q_{10}^{i i} / q_{10}^{j i}\right\} . \\
\Omega_{1 t}^{j i} \cap \Omega_{10}^{j i}=\left\{\omega: z_{1}^{i}(\omega) / z_{1}^{j}(\omega) \leq \min \left\{q_{1 t}^{i i} / q_{1 t}^{j i}, q_{10}^{i i} / q_{10}^{j i}\right\}\right\} .
\end{gathered}
$$

By changing the variable of integration from $\omega$ to pairs of $z_{1}^{i}, z_{1}^{j}$, (A.4) can be written:

$$
\begin{aligned}
\mathcal{I}_{t}^{i}= & \left(\frac{q_{1 t}^{i i}}{P_{1 t}^{i}}\right)^{-\sigma}\left(M_{T t}^{i}+M_{N t}^{i}\right)\left(q_{10}^{i i} \int_{0}^{\infty} \int_{z_{1}^{j} \max \left\{q_{1 t}^{i i} / q_{1 t}^{j i}, q_{10}^{i i} / q_{10}^{j i}\right\}}^{\infty}\left(z_{1}^{i}\right)^{\sigma-1} d F_{1}^{i}\left(z_{1}^{i}\right) d F_{1}^{j}(z) \text { A.5 }\right) \\
& \left.+q_{10}^{j i} \int_{0}^{\infty} \int_{z_{1}^{j} q_{1 t}^{i i} / q_{1 t}^{j i}}^{z_{1}^{j} q_{10}^{i i} / q_{10}^{j i}}\left(z_{1}^{j}\right)^{-1}\left(z_{1}^{i}\right)^{\sigma} d F_{1}^{i}\left(z_{1}^{i}\right) d F_{1}^{j}\left(z_{1}^{j}\right)\right) \\
& +\left(\frac{q_{1 t}^{j i}}{P_{1 t}^{i}}\right)^{-\sigma}\left(M_{T t}^{i}+M_{N t}^{i}\right)\left(q_{10}^{i i} \int_{0}^{\infty} \int_{z_{1}^{j} q_{10}^{i i} / q_{10}^{j i}}^{z_{1}^{j} q_{1 t}^{i i} / q_{1 t}^{j i}}\left(z_{1}^{i}\right)^{-1}\left(z_{1}^{j}\right)^{\sigma} d F_{1}^{i}\left(z_{1}^{i}\right) d F_{1}^{j}\left(z_{1}^{j}\right)\right. \\
& \left.+q_{10}^{j i} \int_{0}^{\infty} \int_{0}^{z_{1}^{j} \min \left\{q_{1 t}^{i i} / q_{1 t}^{j i} q_{10}^{i i} / q_{10}^{j i}\right\}}\left(z_{1}^{j}\right)^{\sigma-1} d F_{1}^{i}\left(z_{1}^{i}\right) d F_{1}^{j}\left(z_{1}^{j}\right)\right)
\end{aligned}
$$

Given equilibrium prices and aggregate quantities, we compute the integral terms numerically. 


\section{Proof of Proposition 1}

Throughout, we make use of the approximation $g\left(x_{t}\right) \approx g^{\prime}(x) x \hat{x}_{t}$, where $\hat{x}_{t}=\log \left(x_{t}\right)-$ $\log (x)$, and a variable without a time subscript refers to the steady state (base period) value.

The approximation for gross output, from equation (A.1), can be written as:

$$
\begin{aligned}
\mathcal{Z}^{i} \hat{\mathcal{Z}}_{t}^{i}= & \left(w^{i} L_{1}^{i}+r^{i} K_{1}^{i}\right) \hat{A}_{1 t}^{i}+\left(w^{i} L_{2}^{i}+r^{i} K_{2}^{i}+P_{1}^{i} M_{T}^{i}\right) \hat{A}_{2 t}^{i}+\left(w^{i} L_{N}^{i}+r^{i} K_{N}^{i}+P_{1}^{i} M_{N}^{i}\right) \hat{A}_{N t}^{i} \\
& -(1-\alpha)\left(w^{i} L_{1}^{i}+r^{i} K_{1}^{i}+\eta\left(w^{i} L_{2}^{i}+r^{i} K_{2}^{i}+P_{1}^{i} M_{T}^{i}+w^{i} L_{N}^{i}+r^{i} K_{N}^{i}+P_{1}^{i} M_{N}^{i}\right)\right) \hat{w}_{t}^{i} \\
& -\alpha\left(w^{i} L_{1}^{i}+r^{i} K_{1}^{i}+\eta\left(w^{i} L_{2}^{i}+r^{i} K_{2}^{i}+P_{1}^{i} M_{T}^{i}+w^{i} L_{N}^{i}+r^{i} K_{N}^{i}+P_{1}^{i} M_{N}^{i}\right)\right) \hat{r}_{t}^{i} \\
& -(1-\eta)\left(w^{i} L_{2}^{i}+r^{i} K_{2}^{i}+P_{1}^{i} M_{T}^{i}+w^{i} L_{N}^{i}+r^{i} K_{N}^{i}+P_{1}^{i} M_{N}^{i}\right) \hat{P}_{1 t}^{i} \\
& +\left(w^{i} L_{1}^{i}+w^{i} L_{2}^{i}+w^{i} L_{N}^{i}\right) \hat{w}_{t}^{i}+\left(r^{i} K_{1}^{i}+r^{i} K_{2}^{i}+r^{i} K_{N}^{i}\right) \hat{r}_{t}^{i}+\left(P_{1}^{i} M_{T}^{i}+P_{1}^{i} M_{N}^{i}\right) \hat{P}_{1 t}^{i} \\
& +w^{i} L_{1}^{i} \hat{L}_{1 t}^{i}+w^{i} L_{2}^{i} \hat{L}_{2 t}^{i}+w^{i} L_{N}^{i} \hat{L}_{N t}^{i}+r^{i} K_{1}^{i} \hat{K}_{1 t}^{i}+r^{i} K_{2}^{i} \hat{K}_{2 t}^{i}+r^{i} K_{N}^{i} \hat{K}_{N t}^{i} \\
& +P_{1}^{i} M_{T}^{i} \hat{M}_{T t}^{i}+P_{1}^{i} M_{N}^{i} \hat{M}_{N t}^{i}+\Xi_{1} \hat{\Xi}_{1 t}^{i}+\Xi_{2} \hat{\Xi}_{2 t}^{i},
\end{aligned}
$$

where $\Xi_{1 t}$ and $\Xi_{2 t}$ are the terms in (A.2) and (A.3). This expression can further be reduced to $^{19}$

$$
\begin{aligned}
\mathcal{Z}^{i} \hat{\mathcal{Z}}_{t}^{i}= & \left(w^{i} L_{1}^{i}+r^{i} K_{1}^{i}\right) \hat{A}_{1 t}^{i}+\left(w^{i} L_{2}^{i}+r^{i} K_{2}^{i}+P_{1}^{i} M_{T}^{i}\right) \hat{A}_{2 t}^{i}+\left(w^{i} L_{N}^{i}+r^{i} K_{N}^{i}+P_{1}^{i} M_{N}^{i}\right) \hat{A}_{N t}^{i} \\
& +w^{i} L^{i} \hat{L}_{t}^{i}+r^{i} K^{i} \hat{K}_{t}^{i}+P_{1}^{i} M_{T}^{i} \hat{M}_{T t}^{i}+P_{1}^{i} M_{N}^{i} \hat{M}_{N t}^{i} .
\end{aligned}
$$

\footnotetext{
${ }^{19} \Xi_{1 t}$ and $\Xi_{2 t}$ equal zero in the steady state, and so $\log$ deviations of the form $\Xi_{s}\left(\log \Xi_{s t}-\log \Xi_{s}\right)$ are not technically well-defined, but take the value zero when considered as the limit of $\left(\Xi_{s}+\varepsilon\right)\left(\log \left(\Xi_{s t}+\varepsilon\right)-\log \left(\Xi_{s}+\varepsilon\right)\right)$ as $\varepsilon \rightarrow 0$.
} 
The real value of intermediate inputs, in (A.5), can be written:

$$
\mathcal{I}_{t}^{i}=\left(M_{T t}^{i}+M_{N t}^{i}\right)\left(\left(\frac{q_{1 t}^{i i}}{P_{1 t}^{i}}\right)^{-\sigma}\left(q_{10}^{i i} I_{d d t}^{i}+q_{10}^{j i} I_{m d t}^{i}\right)+\left(\frac{q_{1 t}^{j i}}{P_{1 t}^{i}}\right)^{-\sigma}\left(q_{10}^{i i} I_{m d t}^{i}+q_{10}^{j i} I_{m m t}^{i}\right)\right)
$$

where the term $I_{d d 1 t}^{i}$ refers to the integral term in (A.5) over the set of goods that country $i$ purchases domestically in both periods 0 and $t$. (Hence the mnemonic $d d$ in the subscript). The approximation of $\mathcal{I}_{t}^{i}$ is then given by:

$$
\begin{aligned}
& \mathcal{I}^{i} \hat{\mathcal{I}}_{t}^{i}=\left(M_{T}^{i}+M_{N}^{i}\right)\left(\frac{q_{1}^{i i}}{P_{1}^{i}}\right)^{-\sigma} q_{1}^{i i} I_{d d}^{i} \hat{I}_{d d t}^{i}+\left(M_{T}^{i}+M_{N}^{i}\right)\left(\frac{q_{1}^{i i}}{P_{1}^{i}}\right)^{-\sigma} q_{1}^{j i} I_{m d}^{i} \hat{I}_{m d t}^{i} \\
& +\left(M_{T}^{i}+M_{N}^{i}\right)\left(\frac{q_{1}^{j i}}{P_{1}^{i}}\right)^{-\sigma} q_{1}^{i i} I_{d m}^{i} \hat{I}_{d m t}^{i}+\left(M_{T}^{i}+M_{N}^{i}\right)\left(\frac{q_{1}^{j i}}{P_{1}^{i}}\right)^{-\sigma} q_{1}^{j i} I_{m m}^{i} \hat{I}_{m m t}^{i} \\
& +\left(M_{T}^{i}+M_{N}^{i}\right) \sigma\left(\left(\frac{q_{1}^{i i}}{P_{1}^{i}}\right)^{-\sigma}\left(q_{1}^{i i} I_{d d}^{i}+q_{1}^{j i} I_{m d}^{i}\right)+\left(\frac{q_{1}^{j i}}{P_{1}^{i}}\right)^{-\sigma}\left(q_{1}^{i i} I_{m d}^{i}+q_{1}^{j i} I_{m m}^{i}\right)\right) \hat{P}_{1 t}^{i} \\
& \quad-\left(M_{T}^{i}+M_{N}^{i}\right) \sigma\left(\left(\frac{q_{1}^{i i}}{P_{1}^{i}}\right)^{-\sigma}\left(q_{1}^{i i} I_{d d}^{i}+q_{1}^{j i} I_{m d}^{i}\right) \hat{q}_{1 t}^{i i}-\left(\frac{q_{1}^{j i}}{P_{1}^{i}}\right)^{-\sigma}\left(q_{1}^{i i} I_{d m}^{i}+q_{1}^{j i} I_{m m}^{i}\right) \hat{q}_{1 t}^{j i}\right) \\
& \quad+\left(\left(\frac{q_{1}^{i i}}{P_{1}^{i}}\right)^{-\sigma}\left(q_{1}^{i i} I_{d d}^{i}+q_{1}^{j i} I_{m d}^{i}\right)+\left(\frac{q_{1}^{j i}}{P_{1}^{i}}\right)^{-\sigma}\left(q_{1}^{i i} I_{d m}^{i}+q_{1}^{j i} I_{m m}^{i}\right)\right)\left(M_{T}^{i} \hat{M}_{T t}^{i}+M_{N}^{i} \hat{M}_{N t}^{i}\right) .
\end{aligned}
$$

To proceed, we suppose that $\frac{q_{1 t}^{i i}}{q_{1 t}^{j i}}>\frac{q_{10}^{i i}}{q_{10}^{j i}}\left(\right.$ the case $\frac{q_{1 t}^{i i}}{q_{1 t}^{j i}} \leq \frac{q_{10}^{i i}}{q_{10}^{j i}}$ is similar), so that the $I$ terms are equal to:

$$
\begin{aligned}
I_{d d t}^{i} & =\int_{0}^{\infty} \int_{z_{1}^{j} q_{t}^{i i} / q_{t}^{j i}}^{\infty}\left(z_{1}^{i}\right)^{\sigma-1} d F_{1}^{i}\left(z_{1}^{i}\right) d F_{1}^{j}\left(z_{1}^{j}\right), \\
I_{m d t}^{i} & =\int_{0}^{\infty} \int_{z_{1}^{j} q_{t}^{i i} / q_{t}^{j i}}^{z^{j i} / q_{0}^{j i}}\left(z^{f}\right)^{-1}\left(z_{1}^{i}\right)^{\sigma} d F_{1}^{i}\left(z_{1}^{i}\right) d F_{1}^{j}\left(z_{1}^{j}\right), \\
I_{d m t}^{i} & =\int_{0}^{\infty} \int_{z_{1}^{j} q_{0}^{i i} / q_{0}^{j i}}^{z^{j} q_{t}^{i i} / q_{t}^{j i}}\left(z_{1}^{i}\right)^{-1}\left(z^{j}\right)^{\sigma} d F_{1}^{i}\left(z_{1}^{i}\right) d F_{1}^{j}\left(z_{1}^{j}\right), \\
I_{m m t}^{i} & =\int_{0}^{\infty} \int_{0}^{z_{1}^{j} q_{0}^{i i} / q_{0}^{j i}}\left(z^{j}\right)^{\sigma-1} d F_{1}^{i}\left(z_{1}^{i}\right) d F_{1}^{j}\left(z_{1}^{j}\right) .
\end{aligned}
$$


These can be approximated as:

$$
\begin{aligned}
I_{d d}^{i} \hat{I}_{d d t}^{i} & =-\left(\hat{q}_{1 t}^{i i}-\hat{q}_{1 t}^{j i}\right) \int_{0}^{\infty}\left(z_{1}^{j} q_{1}^{i i} / q_{1}^{j i}\right)^{\sigma} f_{1}^{i}\left(z_{1}^{j} q_{1}^{i i} / q_{1}^{j i}\right) d F_{1}^{j}\left(z_{1}^{j}\right), \\
I_{d m}^{i} \hat{I}_{d m t}^{i} & =\left(\hat{q}_{1 t}^{i i}-\hat{q}_{1 t}^{j i}\right) \int_{0}^{\infty}\left(f_{1}^{i}\left(z_{1}^{j} q_{1}^{i i} / q_{1}^{j i}\right)\right)\left(z_{1}^{j}\right)^{\sigma} d F_{1}^{j}\left(z_{1}^{j}\right) \\
I_{m d}^{i} \hat{I}_{m d t}^{i} & =I_{m m}^{i} \hat{I}_{m m t}^{i}=0
\end{aligned}
$$

where $f_{1}^{i}$ is the pdf of the distribution $F_{1}^{i}$. Now, the price index $P_{1 t}^{i}$ can be written as:

$$
\left(P_{1 t}^{i}\right)^{1-\sigma}=\int_{0}^{\infty}\left(\int_{z_{1}^{j} q_{1 t}^{i i} / q_{1 t}^{j i}}^{\infty}\left(\frac{q_{1 t}^{i i}}{z_{1}^{i}}\right)^{1-\sigma} d F_{1}^{i}\left(z_{1}^{i}\right)+\int_{0}^{z_{1}^{j} q_{1 t}^{i i} / q_{1 t}^{j i}}\left(\frac{q_{1 t}^{j i}}{z_{1}^{j}}\right)^{1-\sigma} d F_{1}^{i}\left(z_{1}^{i}\right)\right) d F_{1}^{j}\left(z_{1}^{j}\right)
$$

So that we can write:

$$
\left(P_{1}^{i}\right)^{1-\sigma} \hat{P}_{1 t}^{i}=\left(q_{1}^{i i}\right)^{1-\sigma} I_{d d 1}^{i} \hat{q}_{1 t}^{i i}+\left(q_{1}^{j i}\right)^{1-\sigma} I_{m m 1}^{i} \hat{q}_{1 t}^{j i}
$$

Substituting (A.7) and (A.9) into (A.6), we find:

$$
\mathcal{I}^{i} \hat{\mathcal{I}}_{t}^{i}=P_{1}^{i} M_{T}^{i} \hat{M}_{T t}^{i}+P_{1}^{i} M_{N}^{i} \hat{M}_{N t}^{i}
$$

Using the definition of real GDP in Section IV.,

$$
\begin{aligned}
\mathcal{Y}^{i} \hat{\mathcal{Y}}_{t}^{i}= & \mathcal{Z}^{i} \hat{\mathcal{Z}}_{t}^{i}-\mathcal{I}^{i} \hat{\mathcal{I}}_{t}^{i} \\
= & \left(w^{i} L_{1}^{i}+r^{i} K_{1}^{i}\right) \hat{A}_{1 t}^{i}+\left(w^{i} L_{2}^{i}+r^{i} K_{2}^{i}+P_{1}^{i} M_{T}^{i}\right) \hat{A}_{2 t}^{i}+\left(w^{i} L_{N}^{i}+r^{i} K_{N}^{i}+P_{1}^{i} M_{N}^{i}\right) \hat{A}_{N t}^{i} \\
& +w^{i} L^{i} \hat{L}_{t}^{i}+r^{i} K^{i} \hat{K}_{t}^{i} .
\end{aligned}
$$


The steady state value of $Y^{i}$ is:

$$
Y^{i}=w^{i} L_{1}^{i}+r^{i} K_{1}^{i}+w^{i} L_{2}^{i}+r^{i} K_{2}^{i}+w^{i} L_{N}^{i}+r^{i} K_{N}^{i}
$$

Notice that by definition,

$$
Y^{i}=\mathcal{Y}^{i}
$$

since the steady state prices are the base period prices.

Using the fact that $w^{i} L^{i}=(1-\alpha) Y^{i}$ and $r^{i} K^{i}=\alpha Y^{i}$, and dividing by $\mathcal{Y}^{i}$ we can write:

$$
\hat{\mathcal{Y}}_{t}^{i}=\varphi_{1}^{i} \hat{A}_{1 t}^{i}+\varphi_{2}^{i} \hat{A}_{2 t}^{i}+\varphi_{N}^{i} \hat{A}_{N t}^{i}+(1-\alpha) \hat{L}_{t}^{i}+\alpha \hat{K}_{t}^{i}
$$

where the $\varphi_{1}^{i}, \varphi_{2}^{i}$, and $\varphi_{N}^{i}$ are steady state gross output in each sector relative to GDP:

$$
\begin{aligned}
\varphi_{1}^{i} & =\frac{\left(w^{i} L_{1}^{i}+r^{i} K_{1}^{i}\right)}{Y^{i}}=1-\eta, \\
\varphi_{2}^{i} & =\frac{\left(w^{i} L_{2}^{i}+r^{i} K_{2}^{i}+P_{1}^{i} M_{T}^{i}\right)}{Y^{i}}=\gamma, \\
\varphi_{N}^{i} & =\frac{\left(w^{i} L_{N}^{i}+r^{i} K_{N}^{i}+P_{1}^{i} M_{N}^{i}\right)}{Y^{i}}=1-\gamma .
\end{aligned}
$$

Finally, using the defition (32) we have that

$$
\hat{\mathcal{A}}_{t}^{i}=\varphi_{1}^{i} \hat{A}_{1 t}^{i}+\varphi_{2}^{i} \hat{A}_{2 t}^{i}+\varphi_{N}^{i} \hat{A}_{N t}^{i}
$$

which proves the result. 


\section{Proof of Proposition 2}

Using the expression for the price index (16) for the second stage, and the fact that $w_{t}^{i} L_{t}^{i}=$ $(1-\alpha)\left(w_{t}^{i} L_{t}^{i}+r_{t}^{i} K_{t}^{i}\right)$, real income can be written:

$$
\tilde{Y}_{t}^{i}=\frac{1}{1-\alpha} \frac{w_{t}^{i} L_{t}^{i}}{\left(\left(\Gamma\left(\frac{\theta+1-\sigma}{\theta}\right)\right)^{1 /(1-\sigma)}\left(\Phi_{2 t}^{i}\right)^{-1 / \theta}\right)^{\gamma}\left(P_{N t}^{i}\right)^{\gamma} \gamma^{-\gamma}(1-\gamma)^{\gamma-1}}
$$

Using the (17), $\Phi_{2 t}^{i}$ can be expressed in terms of input prices and $\lambda_{2 t}^{i i}$, the fraction of goods that country $i$ buys from itself in the second stage:

$$
\Phi_{2 t}^{i}=\frac{1}{\lambda_{2 t}^{i i}} T_{2}^{i}\left(\frac{1}{A_{2 t}^{i}}\left(\frac{\left(w_{t}^{i}\right)^{1-\alpha}\left(r_{t}^{i}\right)^{\alpha}}{\eta \alpha^{\alpha}(1-\alpha)^{1-\alpha}}\right)^{\eta}\left(\frac{P_{1 t}^{i}}{1-\eta}\right)^{1-\eta}\right)^{-\theta} .
$$

Now, again using (16) and (17), the stage-1 price index $P_{1 t}^{i}$ can be written:

$$
P_{1 t}^{i}=\left(\Gamma\left(\frac{\theta+1-\sigma}{\theta}\right)\right)^{1 /(1-\sigma)}\left(\frac{1}{\lambda_{1 t}^{i i}} T_{1}^{i}\left(\frac{\left(w_{t}^{i}\right)^{1-\alpha}\left(r_{t}^{i}\right)^{\alpha}}{A_{1 t}^{i} \alpha^{\alpha}(1-\alpha)^{1-\alpha}}\right)^{-\theta}\right)^{-1 / \theta}
$$

Plugging (A.10), (A.11) and (20) into the expression for real income, and using the fact that the aggregate capital/ labor ratio is $K_{t}^{i} / L_{t}^{i}=\alpha w_{t}^{i} /\left((1-\alpha) r_{t}^{i}\right)$,

$$
\tilde{Y}_{t}^{i}=\Delta^{i}\left(\lambda_{1 t}^{i i}\right)^{-(1-\eta) / \theta}\left(\lambda_{2 t}^{i i}\right)^{-\gamma / \theta}\left(A_{1 t}^{i}\right)^{1-\eta}\left(A_{2 t}^{i}\right)^{\gamma}\left(A_{N t}^{i}\right)^{1-\gamma}\left(K_{t}^{i}\right)^{\alpha}\left(L_{t}^{i}\right)^{1-\alpha}
$$

and

$$
\tilde{A}_{t}^{i}=\Delta^{i}\left(\lambda_{1 t}^{i i}\right)^{-(1-\eta) / \theta}\left(\lambda_{2 t}^{i i}\right)^{-\gamma / \theta}\left(A_{1 t}^{i}\right)^{1-\eta}\left(A_{2 t}^{i}\right)^{\gamma}\left(A_{N t}^{i}\right)^{1-\gamma}
$$

where $\Delta^{i}=\left(T_{1}^{i}\right)^{(1-\eta) / \theta}\left(T_{2}^{i}\right)^{\gamma / \theta} \eta^{\eta}(1-\eta)^{1-\eta} \gamma^{\gamma}(1-\gamma)^{1-\gamma}\left(\Gamma\left(\frac{\theta+1-\sigma}{\theta}\right)\right)^{\frac{\eta-\gamma-1}{1-\sigma}}$. 